\title{
UN IMPRESOR ANTE LA CRISIS DE LAS LUCES: FERMÍN VILLALPANDO (1794-1830)
}

\author{
GABRIEL SÁNCHEZ ESPINOSA \\ Queen's University Belfast
}

En 1822, cuando José Blanco White, desde la distancia física y temporal, quiso pintar a sus lectores ingleses la inanidad del mercado editorial español en los años previos a la Guerra de la Independencia, en implícita comparación con el pujante contexto británico, escribió lo siguiente:

Years pass with us without the publication of any original work. A few translations from the French, with now and then a sermon, is all the Madrid Gazette can muster to fill up its page of advertisements. A compilation, entitled $E l$ Viagero Universal, and the translation of Guthrie's Grammar of Geography, are looked upon as efforts both of literary industry and commercial enterprise ${ }^{1}$.

Si a los lectores británicos de Blanco dichas obras les parecerían de lo más común, en la España de entresiglos no dejaron de constituir un cierto éxito comercial y editorial, sobre todo si tenemos en cuenta que estaban constituidas por un significativo número de volúmenes, cuyos conjuntos llegaron a completarse. Curiosamente, ambas obras salieron de las prensas del mismo taller madrileño, la imprenta de Fermín Villalpando.

El viagero universal o Noticia del mundo antiguo y nuevo, Obra compuesta en francés por Mr. De Laporte, y traducida al castellano, corregido el original e ilustrado con notas por D. P. E. P. —es decir, don Pedro Estala, presbítero-, se publicó entre 1795 y 1801 por entregas, en cuadernillos de algo más de cien páginas que se vendían sueltos. Tres cuadernillos formaban un tomo de unas 380 páginas y la obra completa alcanzó 39 volúmenes en octavo, a los que se sumaron por último cuatro suplementarios a los cuatro primeros. Las 16.325 páginas que totaliza la obra fueron el producto de un acuerdo formalizado en mayo de 1795 entre Estala y el inversionista Manuel Alonso Rodríguez, que formaron sociedad «a pérdidas y

1 J. Blanco White, Letters from Spain by don Leucadio Doblado, London, Henry Colburn and Co., 1822, p. 384. Se trata de la carta 11, fechada en Madrid, ...1807. Blanco residía en Inglaterra desde febrero de 1810.

Rlit, LXVII, 134 (2005), 373-409 
ganancias por mitad, descontados y abonados que fuesen a Rodríguez todos los gastos que hubiese adelantado» ${ }^{2}$. Por su parte, los catorce volúmenes en octavo de la Geografia universal, descriptiva, histórica, industrial y comercial, de las quatro partes del mundo escrita en ingles por Guillermo Guthrie; traducida al frances por Fray Noel; y de la segunda edicion en esta lengua á la española por D. J. I. C., traducción de la Geographical, Historical, and Commercial Grammar (1770) del escocés William Guthrie (¿1708?-1770), publicada por vez primera en francés en 1801, fueron apareciendo entre 1804 y 1814.

El vallisoletano Fermín Villalpando, nacido en 1766, hijo de don Gaspar Villalpando, natural de la Villa de Valderas de Campos, y doña Rosa García, que lo fue de Medina del Campo, se afincó en Madrid hacia 1780, con 14 años. La imprenta que llevó su nombre publicó sus primeros libros en 1794 y continuaría su actividad hasta su muerte ocurrida en Madrid el 19 de febrero de 1829, manteniéndose la empresa familiar tan sólo dos años más, ese mismo 1829 y el siguiente 1830 bajo la razón social Imprenta de la Viuda de Villalpando. Es de suponer que antes de abrir su propia imprenta, Villalpando hubiera aprendido su oficio y adquirido experiencia como aprendiz y oficial junto a algún impresor madrileño todavía sin identificar. Fermín Villalpando casó con la también vallisoletana Margarita Guerra ${ }^{3}$, nacida en 1770, residente en la villa y Corte desde 1784, hija de don José Guerra y doña Nicolasa Acosta, naturales de Valladolid. El matrimonio Villalpando no tuvo hijos.

Villalpando fue un impresor al servicio de los hombres de letras y los libreros-editores del Madrid de su tiempo; hasta donde sabemos, no fue nunca un impresor-editor o un impresor-librero como lo fueron los Sancha. Hasta 1800 , sus libros aparecieron indistintamente bajo el pie en la imprenta de Fermín Villalpando o, el más ocasional, utilizando también su segundo nombre de pila, en la imprenta de Fermín Tadeo Villalpando, nombre compuesto que no utiliza a partir del nuevo siglo. En 1795 la imprenta estaba domiciliada en la calle de Hortaleza, según nos informa la portada de La Diana

\footnotetext{
${ }^{2}$ En AHN Consejos, leg. 9395, exp. 49. Vid. J. Dowling, «Don Pedro Estala, peripatético», en M. Vidal TiBbITS (ed.), Studies in honor of Gilberto Paolini, Newark (DE), Juan de la Cuesta Press, 1996, pp. 129-139 y M.-E. ARENAS CruZ, Pedro Estala, vida y obra. Una aportación a la teoría literaria del siglo XVIII español, Madrid, CSIC, 2003, especialmente las pp. 436-449. En 1799 se vendía en la librería de Antonio del Castillo una Coleccion general de los trages que usan actualmente todas las naciones del mundo descubierto... obra muy util y en especial para los que tienen la del Viajero universal, que contenía unas 400 estampas que servían de acompañamiento a la obra de La PorteEstala. Vid. J. PANIAGUA PÉREZ, «Los grabados en la obra El Viajero Universal», Revista Española del Pacífico 1 (1991), pp. 47-59. Asimismo, la imprenta madrileña de Espinosa publicó una segunda edición del Viagero universal, cuyo tomo X se tiró en 1813.

${ }^{3}$ Quizá emparentada con el impresor vallisoletano Andrés Guerra Mantilla, activo en los años 60, cuñado del también impresor vallisoletano Tomás de Santander.
} 
de Montemayor ${ }^{4}$, localizándose con seguridad a partir de 1815 en la calle de San José, perpendicular a la Corredera de San Pablo y la calle de la Ballesta, en el barrio conocido como de San Basilio, del cuartel de Maravillas. Debía estar en la parte de atrás del convento de San Felipe Neri, llamado de Portaceli, cuya fachada principal daba a la calle del Desengaño, donde también estaba situado el convento de San Basilio; concretamente, en el cuarto bajo de una casa-pasadizo, según refiere el padrón municipal de 1820. Allí residía el matrimonio Villalpando junto con alguno de sus operarios y los criados de la casa ${ }^{5}$. Es muy posible que la imprenta estuviera situada en la calle de San José con anterioridad a 1815, pues ya en 1802 publicó un folleto asociado con dicho convento de San Basilio 6 .

En octubre de 1817, según el testamento conjunto del matrimonio, la imprenta estaba «compuesta de diferentes fundiciones, y cuatro prensas de imprimir, con todos los enseres pertenecientes a la misma y varias impresiones de libros en paquetes y encuadernados, todo propio y privativo nuestro» ${ }^{7}$. Quizá esta breve noticia pueda completarse cuando se hallen la carta de dote y declaración de bienes y caudales efectuadas al tiempo de su matrimonio, que tuvo lugar con posterioridad al establecimiento de la imprenta. En 1770, las veinticuatro imprentas madrileñas reunían un total de 113 prensas, con una media de 4,5 prensas por taller ${ }^{8}$, mientras que a la altura de 1775 , la mayor imprenta de Barcelona, la del impresor y librero Carlos Gibert y Tutó

${ }^{4}$ J. DE MONTEMAYOR, La Diana... parte primera. Su editor Don Fermin Thadeo Villalpando, impresor en esta Corte, Madrid, se hallará en la Imprenta del Editor, calle de Hortaleza, y en la librería de Escribano, calle de las Carretas, 1795, [16] + 416 pp., $8^{\circ}$. Ejemplar en Fundación Universitaria Española (Madrid), signatura XIV/1169.

5 Según podemos componer a partir de la información incluida en el padrón de 1820 (Archivo de la Villa, Estadística 3-5-3, «Barrio de San Basilio», p. 53v.) y la contenida en el Diario de Madrid de 29 de septiembre de 1815 y 21 de agosto de 1818 , en que se anuncian las Novelas ejemplares y los Trabajos de Persiles y Sigismunda de Cervantes, y los Consejos de un padre a su hijo de Campe, respectivamente. En el domicilio de los Villalpando residían en 1820 su hermana Josefa Villalpando, soltera de 52 años, dos aprendices y un oficial de la imprenta, y los criados Juan García y Francisca Buendía, de 18 y 17 años.

${ }^{6}$ Oración fúnebre que en las honras celebradas por los oficiales del Regimiento de Reales Guardias Españolas de Infanteria, en el Convento de San Basilio de esta Corte, el 8 de agosto de 1802, por el alma del Excelentisimo Señor Don Jose Ibañez Arco, ... dixo el Dr. D. Vicente Navarro, Madrid, Villalpando, 1802, 30 pp., $4^{\circ}$. Ejemplar en BNM, signatura V. E. Caja 498 (27).

7 Testamento conjunto de Fermín Tadeo Villalpando y su mujer Margarita Guerra ante el escribano Dionisio Pérez, 1 de octubre de 1817 (Archivo de Protocolos de Madrid, tomo 23919, fols. 457 y ss.).

${ }^{8}$ L. M. ENCISO RECIO (Nipho y el periodismo español del siglo XVIII, Valladolid, Universidad de Valladolid, 1956, pp. 266-268, nota 110), transcribe la «Lista de todas las imprentas que hay en la Corte, nombres de los impresores y calles donde viven», conservado en AHN Consejos, leg. 50664. 
tenía acondicionadas cuatro prensas ${ }^{9}$. No poseemos todavía datos de conjunto para conocer el número de prensas por taller durante los reinados de Carlos IV y Fernando VII.

En cuanto al número de trabajadores empleados en la imprenta, podemos suponer que cada prensa estaría servida por un oficial y un aprendiz, y para las cuatro cajas serían necesarios dos oficiales y dos aprendices. Esta proporción refleja la división del trabajo habitual en otras imprentas, concretamente en la Imprenta Real. Evidentemente, el número y la distribución de estos operarios podría alterarse o completarse según el cambiante volumen de trabajo de la imprenta. En 1820, residían en casa del impresor el oficial José Martínez, de 22 años de edad, y los aprendices Juan Crisóstomo Castilla y Juan José López, de 13 y 14 años ${ }^{10}$.

Según los datos que hemos reunido ${ }^{11}$, la imprenta Villalpando produjo entre 1794 y 1830 un total de 301 obras, de las que 20 son reediciones de obras salidas de la propia imprenta, y 63 corresponden a obras en más de un volumen -el $21 \%$ - Toda esta producción representa un conjunto de 536 volúmenes distintos. Tras distribuirlas por años, se obtiene el siguiente gráfico que representa la producción quinquenal de la imprenta ${ }^{12}$.

${ }^{9}$ Vid. J. MOLL, «Un memorial del impresor y librero barcelonés Carlos Gibert y Tutó», en De la imprenta al lector. Estudios sobre el libro español de los siglos XVI al XVIII, Madrid, Arco Libros, 1994, pp. 95-107.

${ }_{10}$ Villalpando, en la memoria testamentaria de 11 de octubre de 1828 que adjunta a su testamento de 1817, al disponer sus mandas testamentarias y las condiciones de su enterramiento, alude de forma general a los operarios de su taller: «Item es mi voluntad, que a los oficiales y aprendices así de caja como de prensa que el día de mi fallecimiento se hallen trabajando en esta mi imprenta que se les den a los oficiales veinte reales a cada uno, y a los aprendices diez reales también a cada uno y les pido se sirvan acompañar mi cadáver al campo santo, y que me encomienden a Dios» (Archivo de Protocolos de Madrid, escribano Dionisio Pérez, tomo 23919, fols. 462 y ss.).

${ }^{11}$ Principalmente a partir del Catálogo colectivo del patrimonio bibliográfico español, de la Bibliografía de Autores Españoles del siglo XVIII de F. AGUILAR PIÑAL, del Shorttitle Catalogue of Eighteenth-Century Spanish books in the British Library (1994), del Manual del librero Hispano-Americano de A. Palau y Dulcet, del Catálogo de la Real Biblioteca y de noticias espigadas de aquí y allá en catálogos de librerías anticuarias.

${ }_{12}$ No hemos tenido en cuenta dos obras de las que no sabemos con seguridad el año de impresión: A. von KotZeBue, La misantropía y el arrepentimiento: Drama en cinco actos, en prosa, del teatro alemán de Kotz-bue: Refundido por la ciudadana Molé, actriz del teatro francés, y traducido fielmente por D. A. G. A [Agustín García de Arrieta], Madrid, Villalpando, s.a., $8^{\circ}$, impresa seguramente con posterioridad al estreno en el Coliseo de la Cruz en 1800 de la traducción de Dionisio Solís, que se mantuvo con éxito dieciocho días en cartel —ejemplar en la Universidad de Tejas, en Austin, signatura 862.08/T224/A2/ v.14 (5) - ; y la Corona dolorosa de María Santísima: modo de rezarla y ofrecerla, con el sumario de indulgencias para todos los fieles que reciben el Escapulario y Corona de Dolores, Madrid, en la imprenta de Villalpando: se hallará en la Portería de la Casa Profesa de PP. Clérigos Reglares Ministros de los Enfermos..., s.a., $8^{\circ}$, con una estampa de la Dolorosa grabada y dibujada por José Jimeno (Valencia, 1757-Madrid, después de 1807), con ejemplar en el convento madrileño de La Encarnación, signatura C/8 (16). 


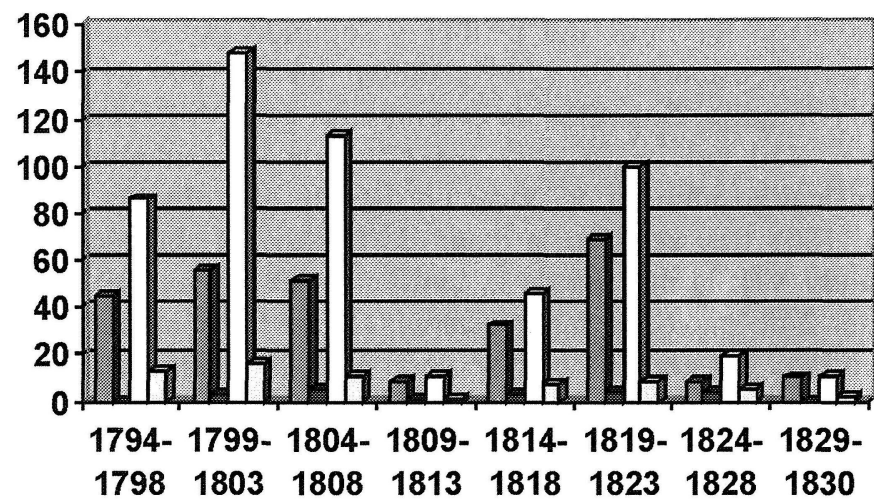

Tobra original reedición $\square$ vols.

$\square$ multivol.

Producción quinquenal de la imprenta Villalpando

Tomando como punto de partida que la década de los ochenta, última del reinado de Carlos III, se caracterizó por el aumento general de la producción de las imprentas españolas, a partir de la cual dio comienzo una etapa de recesión que marcó los últimos años del Antiguo Régimen, observamos aquí cómo la imprenta de Fermín Villalpando, mantuvo unos dignos niveles de producción en sus tres primeros lustros, en los que pasó de producir 45 obras en 86 vols., a producir 59 en 148 vols. para bajar ligeramente a 56 en 113 vols. en el quinquenio que termina en 1808. Los años 1809-1813 son años de crisis, con sus 9 obras en 11 vols., que empieza a remontarse en el lustro 18141818 con sus 35 obras en 46 vols., de las que se salta a 73 obras en 100 vols. durante 1819-1823, cayendo consiguientemente a 12 en 19 vols. para los años 1824-1828. Curiosamente, 1829-1830, ya bajo el pie de imprenta de la Viuda de Villalpando, significan un cierto remonte con sus 10 obras en 11 vols.

Por supuesto, este gráfico ha de compaginarse con otro en que se distribuya la producción de acuerdo con el contexto político.
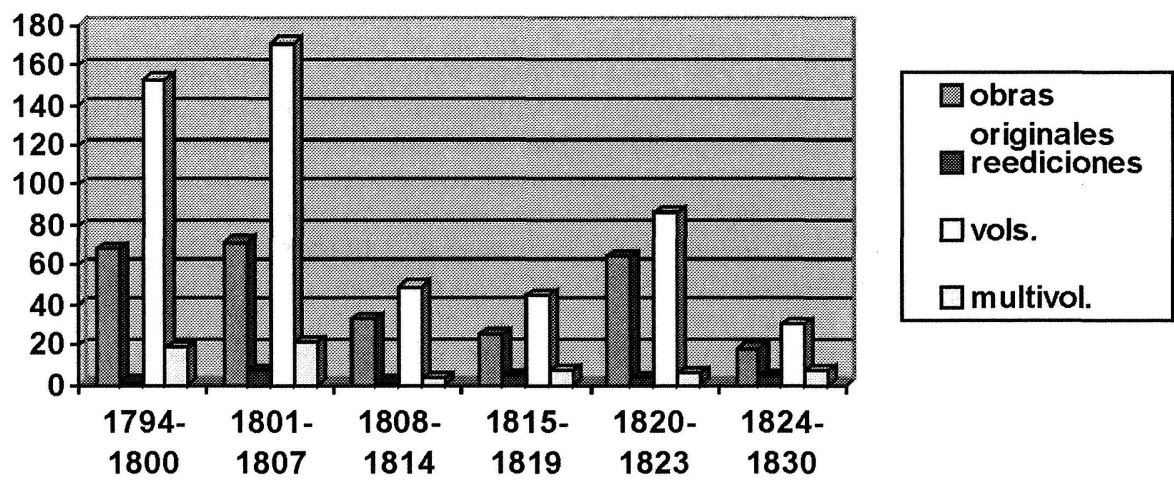

Producción de la imprenta Villalpando en relación con el contexto político 
Los años 1794-1807 son los años del primer y segundo gobierno de Godoy con el paréntesis entre marzo de 1798 y diciembre de 1800 de los gobiernos de Saavedra y Urquijo. Son años de crecimiento para Villalpando, que pasa de 69 obras en 153 vols. a 78 obras en 171 vols., afrontando en estos periodos un significativo número de obras en más de un volumen, 19 y 21, respectivamente. 1808 trae consigo la caída de Godoy, la abdicación de Carlos IV en Fernando VII, la marcha de la familia real a Francia, el levantamiento popular del 2 de mayo, la fugaz estancia de José Bonaparte en Madrid en julio y la entrada del emperador Napoleón el 4 de diciembre. En ese año, el taller Villalpando imprime 13 nuevas obras, 9 de ellas folletos directamente relacionados con la inestable situación política, inequivocamente inclinadas a expresar un punto de vista antifrancés y patriota ${ }^{13}$. Tras la derrota francesa en Bailén y la entrada de las tropas de Castaños en Madrid a mediados de agosto, se ordena el embargo de los bienes de los partidarios más significados de José Bonaparte, entre los que hay que contar al canónigo de Toledo Pedro Estala, que habían abandonado la capital acompañando a los franceses. Esta circunstancia provoca que Fermín Villalpando presente en septiembre una reclamación ante el Consejo para recuperar lo que Estala le debía: 5.318 reales por la impresión de los tomos XVIII, XIX, XX y XXI del Compendio de la Historia Natural de Buffon traducido y editado por Estala $^{14}$, producidos entre 1806 y 1808. Se especifica en la reclamación el importe de la impresión de cada uno de estos tomos. El XVIII había costado 1.824 reales; cada uno de los otros tres, 1.734 reales.

Mi parte ha pedido a Estala muchas veces este importe de impresión, pero siempre o casi siempre en vano, por que sólo ha tirado a dar buenas palabras, y hacer ofertas de pagar en tiempos mas desahogados para él. Sin embargo a fuerza de ruegos y de apuros ha podido Villalpando conseguir que de los productos de

${ }_{13}$ Así, por ejemplo: Segunda parte en la que se indican varias reflexînes que persuaden que la presentación de nuestro amado Fernando VII á Bonaparte en Bayona, fué disposición divina para los altos fines que se expresarán, y para que la nación española se animase á sacudir el yugo de aquel tirano, á vista de su infame conducta, disponiendo al efecto formidables exércitos con presteza, como lo ha hecho, nombrando generales que los dirijan y manden, Madrid, Imprenta de Villalpando, 1808, [8] pp., $4^{\circ}$, ejemplar en AHN. Biblioteca Auxiliar. Consejos 50703/146; o el folleto del canónigo José Aguado, Oración fúnebre que en las solemnes exequias celebradas el dia ocho de agosto de este presente año en la Santa Iglesia Catedral de Avila por las almas de los valerosos españoles que han muerto en la guerra contra los franceses..., Madrid, Villalpando, 1808, 24 pp., $8^{\circ}$, ejemplar en BNM, signatura VE 510 (25); o el Himno al excelentísimo señor D. José Palafox y Melci... por un americano, Madrid, Imprenta de Villalpando, 1808, 13 pp., $8^{\circ}$; Inc.: «Laurel inmortal... Exp.: ...de Francia terror.» Ejemplar en Palacio Real de Madrid, signatura VIII/18325 (5).

${ }^{14}$ CONDE DE BUfFON [Georges Louis Leclerc], Compendio de la Historia Natural de Buffon, clasificado según el sistema de Linneo por Renato Ricardo Castel, traducido e ilustrado por Don Pedro Estala, Madrid, Villalpando, 1802-1811, 22 vols., $8^{\circ}$. Ejemplar en BNM, signatura 5-2540/61. 
esta obra impresa en su casa se le hayan entregado en varias partidas, y ocasiones, hasta la cantidad de 1.708 reales, de manera que hoy resulta estarle debiendo Estala 5.318 reales después de rebajados los 1.708 ya $\operatorname{cobrados}^{15}$.

Paralelamente, Ignacio de la Peña, vecino y administrador de correos de la ciudad de Sigüenza, le reclama a Estala la suma de 9.008 reales remanentes de la deuda que tiene pendiente con él, pues

ha remitido en diferentes partidas y ocasiones para el presbítero don Pedro Estala doscientas y doce resmas de papel a precio convenido de cincuenta y dos reales cada una. Todas estas 212 resmas de papel fueron a parar de orden de Estala a la imprenta de don Fermín Villalpando en la que se emplearon y sirvieron para la obra del Compendio de Bufon, que ha dado a luz en varias ocasiones y por tomos sueltos el citado don Pedro Estala. Aunque el fabricante de este papel don Ignacio de la Peña, ha pedido a Estala muchas veces su total importe, no ha podido conseguir hasta ahora su pago completo, que asciende segun el precio mencionado a once mil y veinte y cuatro reales. A fuerza de ruegos, de suplicas, y de amenazas hechas a Estala, de orden de éste entregó el impresor Villalpando a mi parte el dia doce de noviembre de 1806 , mil y quinientos reales, y en 20 de mayo de 1807, quinientos diez y seis reales cuyas dos partidas componen la suma de dos mil y diez y seis reales, de manera que rebajados de los once mil veinte y cuatro reales, resulta incontestablemente que don Pedro Estala debe hoy a don Ignacio de la Peña la cantidad de nueve mil y ocho reales de vellón, según resultará de los apuntes o cuentas hallados o encontrados en casa del presbítero Estala.

Estas reclamaciones de Villalpando y Peña probablemente han de entenderse como maniobras preventivas para recuperar alguna parte de lo adeudado por Estala, que tenía abiertos varios expedientes por deudas ante el Consejo de Castilla. No sabemos qué hizo Villalpando durante los años 1809 a 1811, en los que no sale de sus prensas ninguna obra nueva, siendo el único síntoma de cierta continuidad la impresión en 1811 del volumen XXII y último del Compendio de Buffon del mencionado Estala. En 1812, Villalpando publica tres obras: La escuela de los maridos de Molière en traducción de Moratín y, entre la entrada de Wellington el 12 de agosto y la vuelta de los franceses el 7 de diciembre dos folletos relativos a las Cortes ${ }^{16}$. En 1813, tras

${ }^{15}$ En AHN, Consejos, leg. 9345, 48. Vid. M.-E. ARENAS CRUZ, ob. cit., pp. 124-126.

${ }^{16}$ MOLIÈRE, La escuela de los maridos. Comedia escrita en francés por Juan Bautista Molière, y traducida á nuestra lengua por Inarco Celenio P. A., Madrid, Imprenta de Villalpando, 1812, 128 pp., 8. Ejemplar en BNM, T-10541; H.D.M.T., Reflexîones al señor público, para que suplique á las Cortes generales la extincion de los frayles: en esta obrita se exponen con sencillez y claridad las razones que exîgen la extincion de Frayles. Por H.D.M.T., Madrid, en la imprenta de Villalpando: se hallará en la Librería de Villareal, calle de las Carretas, 1812, 15 pp., [1] en blanco, $4^{\circ}$. Ejemplar en Palacio Real de Madrid, III/6596 (4); Carta Cuarta: contiene un Manual cristiano español importantísimo para el mayor acierto en las elecciones a Diputados de Cortes para las ordinarias del próximo 1813... y resoluciones de la Suprema Regencia del Reino, relativas al intento..., Madrid, Villalpando, 1812, 11 pp., 4. Ejemplar en BNM, signatura V.E./729-57 (IV). 
la retirada francesa del 27 de mayo, Villalpando imprime cinco nuevas obras, entre ellas un folleto relativo al líder guerrillero Mina y la relevante Teoría de las Cortes del canónigo de San Isidro Francisco Martínez Marina ${ }^{17}$. En 1814 aparecen 12 nuevas obras, algunas de ellas evidentemente anteriores al 4 de mayo, en que Fernando VII anula la Constitución, como debió ser el caso de un folleto en elogio de la vida y acciones del Empecinado y el periódico El Fiscal patriótico de España, de José Manuel Jecebek, cuyo número 56 y último corresponde al 15 de abril ${ }^{18}$. A partir de la restauración del absolutismo, Villalpando confecciona diversos manifiestos de servicios llevados a cabo por instituciones y particulares durante los años de ausencia del rey, así como algunos sermonarios ${ }^{19}$. Se deduce de todo esto que Fermín Villalpando no se afrancesó y se inclinó, no sabemos en qué grado, al partido de los patriotas. En junio y diciembre de 1814, el impresor elevó sendos memoriales a la nueva administración real pidiendo la gracia de ser nombrado impresor de cámara de S.M., para lo que alegó como méritos haber «tenido el honor de haber impreso de orden del Serenísimo Señor Infante Don Antonio el Análisis de las aguas y baños de Sacedón, un librito de oraciones y todo lo demás que S.A. le ha mandado. Asimismo tuvo la honra de de imprimir de orden de V.M. siendo Príncipe de Asturias la obra titulada Historia de Roma, la que no se concluyó con motivo de lo ocurrido en el Real Sitio del Escorial, y se dio orden para que se suspendiese la impresión». Gracia que obtuvo el 2 de marzo de 1815, en que Fernando VII le concedió «los honores y uso de uniforme de impresor de cámara con las prerrogativas que le son anexas... en atención a sus méritos y buenas circunstancias». El 12 de marzo a las once de la mañana, el impresor juró fidelidad a S.M. ante el sumiller de corps, marqués de Ariza y Estepa, aunque no se le expi-

17 [J.F.J.H.G.], Breve noticia del origen, progresos y estado actual de las tropas al mando del Mariscal de Campo Don Francisco Espoz y Mina, Madrid, Imprenta de Villalpando, 1813, 20 pp., $4^{\circ}$. Ejemplar en BNM, V.E./751-15; Francisco MARTíNEZ MARINA, Teoría de las Cortes o grandes Juntas nacionales de los reinos de León y Castilla, monumentos de su constitución política y de la soberanía del pueblo, Madrid, Imprenta de Fermín Villalpando, 1813, 3 vols., $4^{\circ}$. Ejemplar en RAE, S. Coms. 13-E-19/ S. Coms. 13-E-21.

${ }_{18}$ Apuntes de la vida y hechos militares del brigadier Don Juan Martín Diez el Empecinado por un admirador de ellos, Madrid, Imprenta de Fermín Villalpando, 1814, 91 pp. + [1], 4 . Ejemplar en Palacio Real de Madrid, IV/1184; El Fiscal patriótico de España, Madrid, Imprenta de Villalpando, 1814, 4. Ejemplar en BNM, R-60043 (28).

19 Así, por ejemplo, el Manifiesto de los servicios hechos por la Real Maestranza de Ronda en defensa de la Nación española y fiestas practicadas en la celebridad de la feliz restauración de nuestro Rey y Señor D. Fernando VII al Trono de sus mayores, Madrid, Imprenta de Fermín Villalpando, 1814, 35 pp., $4^{\circ}$, con portada alegórica dibujada por Urbano de Castro y grabada por Albuerna. Ejemplar en RAH, 16/3154. O, los Sermones para todas las dominicas del año, Madrid, Villalpando, 1814, 3 vols., $4^{\circ}$, obra de Joaquín Antonio de Eguileta, aparecida por vez primera en 1788. Ejemplar en Franciscanos (Santiago), signatura, 11-7-20. 
dió el título hasta el 2 de febrero de 1817, tras satisfacer a finales de enero los 100 reales y 10 maravedís que debía en concepto de media annata ${ }^{20}$.

La recesión iniciada con la guerra se profundiza durante el Sexenio Absolutista. Las prensas de Villalpando producen sólo 29 obras en 45 vols., volumen menor que el elaborado durante los agitados e inciertos años del periodo anterior. Se imprimen obras que no suponen ningún riesgo, ni político ni económico, como es el caso de las ya rancias traducciones que hizo Francisco Mariano Nifo - fallecido en 1803- de algunas obras del marqués de Caracciolo ${ }^{21}$. La situación cambia como de la noche al día a partir del pronunciamiento de Rafael del Riego en Cabezas de San Juan el 1 de enero de 1820, que inaugura el Trienio Constitucional. Durante el Trienio, la oficina de Villalpando imprime un total de 67 obras en 86 vols. Concretamente, 27 obras en 1820 y 30 en 1821 , para reducir fortísimamente su producción en 1822 y 1823 , en que sólo se llevan a cabo 6 y 4 obras, respectivamente. Entre las obras de 1820 destacan los periódicos Tertulia de Maudes y El Compadre del Holgazán; asimismo, la Lógica de Condillac en traducción del recién rehabilitado Valentín de Foronda - que vuelve a reeditarse ese mismo año-, El espíritu de las leyes de Montesquieu traducido por Juan López de Peñalver, junto a obras de destacados liberales como Álvaro Flórez Estrada y Francisco Martínez Marina ${ }^{22}$. En 1821 las prensas de Villalpando imprimen

${ }^{20}$ Memoriales con fecha 4 de junio y 8 de diciembre de 1814 (Archivo de Palacio, sección Personal, caja 1096, exp. 20). Se alude aquí a la obra Análisis de las aguas minerales y termales de Sacedón, que se hizo cuando pasó a tomarlas el Serenísimo Infante D. Antonio, en el mes de julio y agosto del año de 1800, con toda su servidumbre, Madrid, Villalpando, 1801, 44 hs. + 1 estampa plegada, $4^{\circ}$. Ejemplar en Facultad de Medicina de Madrid, signatura 615-79-An. I. En el memorial de junio se da algún dato más relativo a la impresión de la aludida Historia de Roma: «...dio orden para que se suspendiese la impresión, y se ocultase lo impreso, lo que inmediatamente se hizo en una cueva de la habitación de don Pedro Gutiérrez Bueno, boticario de cámara de S.M.» Entre 1800 y 1815, P. Gutiérrez Bueno publicó 13 obras en la oficina Villalpando. Entre ellas una Descripción de los Reales Baños de Arnedillo, y análisis de sus aguas por D. ..., Madrid, Fermín Villalpando, 1801, VIII + 63 pp. +4 hs., $4^{\circ}$. Con dos estampas calcográficas. Ejemplar en BNM V. E. 582 (17). Sobre dicho catedrático de química del Colegio de San Carlos, puede verse P. CARRASCO JARABO, «Vida y obra de Pedro Gutiérrez Bueno», Boletín de la Sociedad Española de Historia de la Farmacia 15 (1964), pp. 154-169; 16 (1965), pp. 10-24, 71-86, 101-118 y 153-177.

${ }^{21}$ MARQUÉS DE CARACCIOLO, Ultima despedida de la Mariscala a sus hijos. Compuesta en francés por el Marqués Caracciolo. Traducida en castellano por D. Francisco Mariano Nifo, Madrid, Villalpando, 1817, VIII + 298 pp., $8^{\circ}$. Ejemplar en Franciscanos (Santiago), signatura 27-15-43.

Clemente XIV, Cartas importantes del papa Clemente XIV. Colección formada por el marques de Caracciolo; traducida del frances al castellano por Francisco Mariano Nifo, Madrid, Imprenta de Villalpando-Librería de Matute, 232 pp., $8^{\circ}$. Ejemplar en Congregación de la Misión de San Vicente de Paúl, Biblioteca Provincial (Madrid), signatura 161-E-22.

${ }^{22}$ Tertulia de Maudes. Nuevo periódico compuesto por D. A. G. V., Madrid, imprenta de D. Fermin Villalpando, 1820, 24 pp., $4^{\circ}$. Ejemplar en Palacio Real de Madrid, VIII/ 
el Tratado de los delitos y de las penas de Beccaria, la Ciencia de la legislación de Caetano Filangieri y el Tratado de economía política de Say, todas ellas traducidas por Juan Sánchez Rivera-; el Comentario sobre el Espíritu de las leyes de Montesquieu de Destutt de Tracy - que se reedita en 1822- y los Tratados de legislación civil y penal de Jeremy Bentham en versiones del antiguo rector de Salamanca Ramón de Salas, que había sido privado de su cátedra de Instituciones Civiles en 1796; el Compendio histórico de los tres primeros años de la Revolución Francesa de Rabaut de SaintEtienne y las Máximas y pensamientos del prisionero de Santa Elena, obra esta última traducida por el editor del Compadre del Holgazán, Manuel Centeno $^{23}$. Significativamente, junto a estas obras directamente implicadas en la transformación política emprendida por el régimen constitucional ${ }^{24}$, Fermín

18229 (2) (1820). Esta publicación periódica de frecuencia semanal, que salía los jueves, cesó el 4 de mayo de 1820. Su editor no admitía suscriptores, circunstancia que llamó la atención en la época y que debió motivar su fracaso. Durante 1820-1821, Villalpando publicó 20 cartas del Compadre del Holgazán y apologista universal de la holgazanería de Manuel Centeno. Hay ejemplar en Real Gran Peña (Madrid), signatura FD 5-8-21 (120) Esta publicación liberal moderada mantuvo a partir de su número quinto, según los comentarios de La Periódico-manía (1820-1821), una viva polémica con El Conservador, al que tacha de afrancesado. Vid. E. Rubio CREMAdES, «La Periódico-manía y la prensa madrileña del Trienio Liberal (II)», en Anales de Literatura Española 5 (1985), pp. 382414, en p. 394.

Etienne BONNOT DE CONDILlaC, Segunda edicion de la lógica de Condillac puesta en diálogo por D. Valentin de Foronda..., Madrid, Imprenta de Villalpando, 1820, XVI + 256 pp., $8^{\circ}$. Ejemplar en la Biblioteca Pública del Estado Antonio Rodríguez Moñino y María Brey (Cáceres), signatura 2/7652.

Álvaro FlóREZ ESTRADA, Representación hecha a S.M.C. el Señor D. Fernando VII en defensa de las Cortes, Madrid, en la Imprenta de Villalpando, 1820, 155 pp., $8^{\circ}$. Ejemplar en Fundación Universitaria Española (Madrid), signatura PEN1/1395.

Francisco MARTínez MARINA, Juicio crítico de la Novísima Recopilación por el ciudadano D. ..., Madrid, Imprenta de Don Fermín Villalpando, 1820, VIII + 335 pp., $4^{\circ}$. Ejemplar en RAH, 3/8862

${ }^{23}$ Cesare BECCARIA, Tratado de los delitos y de las penas escrito en italiano por el marques de Becaria; y traducido al castellano por Juan Rivera, Madrid, Imprenta de Fermin Villalpando, 1821, XIV + 288 pp., $8^{\circ}$. Ejemplar en BNM, signatura 2/21078.

Caetano FILANGIERI, Ciencia de la legislación... Nuevamente traducida por D. Juan Ribera, Imprenta de D. Fermín Villalpando, Madrid, 1821-1822, 6 tomos, $8^{\circ}$. Con retrato grabado por E. Boix. Ejemplar en Real Academia de Ciencias Morales y Políticas, signatura $4367 / 4372$.

Juan Bautista SAY, Tratado de economía política: o exposición sencilla del modo con que se forman, se distribuyen y conservan las riquezas por Juan Bautista Say; nueva traducción por D. Juan Sanchez Ribera, Madrid, Fermín Villalpando-Martínez Dávila, 1821, 2 vols., $4^{\circ}$. Ejemplar en Fundación Universitaria Española (Madrid), signatura XIV/11611162.

CONDE DE DESTUTT DE TRACY, Antoine LOUIS, Comentario sobre el espíritu de las leyes de Montesquieu por el conde Destutt de Tracy; con las observaciones inéditas de Condorcet sobre el libro XXIX de esta obra; traducida del francés al español por Ramón Salas, Madrid, Imprenta de Fermin Villalpando, 1821, XVI +368 pp., $8^{\circ}$. Ejemplar en RAH, $14 / 8425$. 
Villalpando, quizá aprendida la lección que supuso la restauración fernandina de 1814, que sumió a su negocio en una crisis durante el Sexenio Absolutista, parece poner una vela al diablo y otra a Dios diversificando ideológicamente su oferta, por lo que pudiera pasar. De este modo, en 1821 saca a la calle seis folletos debidos a fray Diego José de Cádiz (1743-1801), paradigma en su tiempo de la reacción clerical ante las Luces, maniobra a la que se suman otros cinco folletos del capuchino en 1822, en que sus sermones compartirían taller y quizá caja tipográfica con la Cartilla de economía política de Say y los tomos finales de las obras de Bentham y Filangieri ${ }^{25}$. En 1823 corren parejas la crisis de la monarquía constitucional y la caída de la producción, que apenas se sostiene con dos libros y dos folletos: un sermón de fray Diego José, la edición de una oración pronunciada en las exequias celebradas en 1801 a la muerte de dicho fraile, una letanía al Santísimo Sacramento y una denuncia pública del general don Enrique O'Donnell. A partir de aquí, instalados en la Década Ominosa, bajo la fuerte censura impuesta por el reaccionario ministro Calomarde, la imprenta Villalpando produce en el periodo 1824-1830 22 obras en 30 vols., retrocediendo la producción durante los años 1824-1828, los últimos de Fermín Villalpando, a niveles semejantes a los del lustro 1809-1813. Probablemente, para ventear de algún modo esta fortísima crisis de publicaciones, solicitó el nombramiento de impresor de la mayordomía mayor de Palacio a finales de febrero de 1828 , a lo que sabemos en vano. En 1829-1830, tras su muerte y ahora bajo el sello editorial de su viuda, es apreciable un cierto remonte del negocio, pequeño despunte con el que finalizó esta aventura empresarial.

Jeremy BENTHAM, Tratados de legislacion civil y penal: obra extractada de los manuscritos del señor Jeremias Bentham por Esteban Dumont; $y$ traducida al castellano con comentarios por Ramon Salas, Madrid, Imprenta de D. Fermin Villalpando, 1821-1822, 5 vols., $4^{\circ}$. Ejemplar en Real Academia de Ciencias Morales y Políticas, signatura 5622/ 5626.

Jean Paul RABAUt DE SAINT-ETIENne, Compendio histórico de los tres primeros años de la Revolución Francesa, Madrid, Imprenta de Villalpando, 1821, XVI + 389 pp., $12^{\circ}$. Ejemplar en la Biblioteca Pública del Estado Antonio Rodríguez Moñino y María Brey (Cáceres), signatura 2/8546.

Napoleón BoNAPARTE, Máximas y pensamientos del prisionero de Santa Elena. Traduccion del ingles al frances, y de este al castellano por D. M. C. [Manuel Centeno], Madrid, en la imprenta de Villalpando, 1821, 116 pp., $8^{\circ}$. Ejemplar en el Museo Cerralbo (Madrid), signatura IX-2053 (1).

${ }^{24}$ Vid. al respecto los trabajos de S. SCANDELLARI, "Alcune note sull'influenza di Jeremy Bentham nel Codice penale spagnolo del 1822», Bollettino dell'Archivio Storico sardo di Sassari 10 (1984), pp. 127-181 y «Alcune note sull'influenza di Filangieri nella codificazione penale spagnola del 1822», en Gaetano Filangieri e l'Illuminismo europeo. Atti del Convegno di Vico Equense (14-16 ottobre 1982), Nápoles, Guida, 1991, pp. 519-527.

${ }^{25}$ En AHN, Biblioteca Auxiliar, Clero-Jesuitas, leg. 779/3, n. ${ }^{\circ} 9$, se conservan los prospectos en cuarto que anuncian la apertura de las suscripciones -en la librería de Sojo, calle de Carretas-, para La ciencia de la legislación de Filangieri y los Tratados de Legislación de Bentham. 
Por lo que respecta a la distinción entre libros y folletos, es decir aquellos impresos que no forman volumen cosido y encuadernado, de extensión menor a las cincuenta páginas ${ }^{26}$, al examinar la producción de la imprenta Villalpando entre 1794 y 1830 , establecemos que los libros son 201 -el $67 \%$ - frente a una cifra de 100 folletos -el $33 \%$ - Por su procedencia, el 90 por ciento de los folletos es obra directa de un autor individual, frente a sólo un 10 por ciento de papeles producto de instituciones, como es el caso del Reglamento de la Real Cámara (1825) o las Ordenanzas formadas para el régimen y gobierno del gremio de Fabricantes de Cera de esta Corte $(1830)^{27}$. Al no requerir encuadernación el folleto, papel o panfleto, es el vehículo de los textos más inmediatos a las circunstancias y requerimientos de la actualidad, frente al libro encuadernado que supone un mayor distanciamiento intelectual ante los sucesos del día. Por todo ello puede resultar de interés el distinguir la mayor o menor frecuencia de libros y papeles en los diferentes periodos por los que atravesó la imprenta.

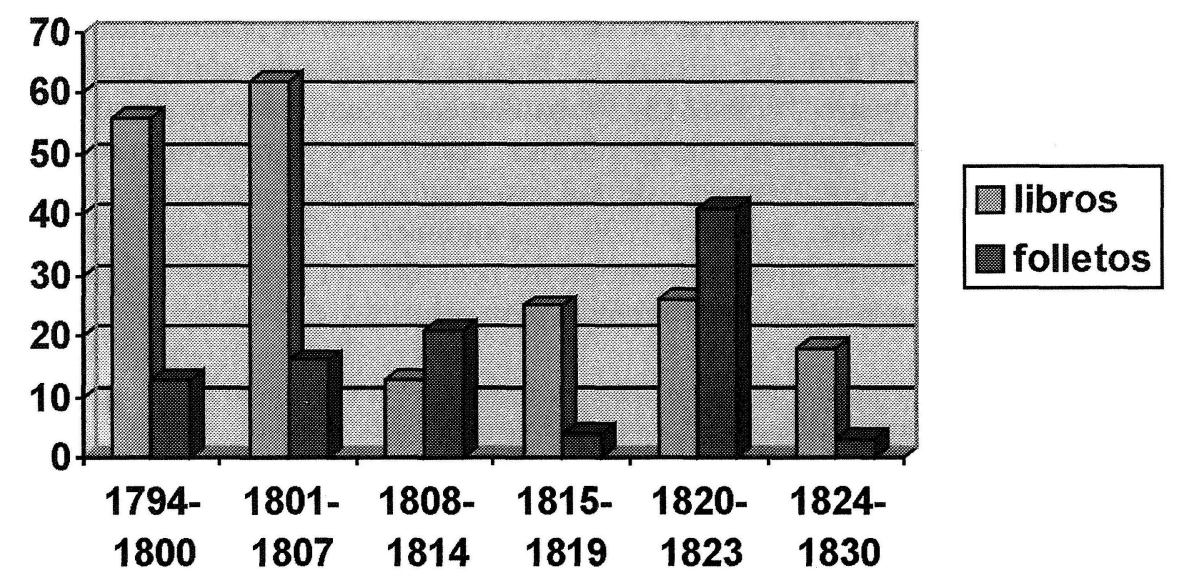

Producción de la imprenta Villalpando en relación con el contexto político (libros / folletos)

${ }^{26}$ Vid. F. LÓPEZ, «Libros y papeles», Bulletin hispanique 99 (1997), pp. 293-307.

${ }^{27}$ Reglamento de la Real Cámara, Madrid, Imprenta de Fermín Villalpando, 1825, 13 pp., $4^{\circ}$. Portada con escudo real y leyenda «Cardano ft». Ejemplar en Palacio Real de Madrid, signatura VIII/15370. Los gastos de impresión y encuadernación de esta obra ascendieron a 5.288 reales de vellón, según cuenta presentada por Villalpando al sumiller de Corps, duque de Híjar, a primeros de mayo de 1825 (Archivo de Palacio, sección Personal, caja 1096, exp. 20).

Ordenanzas formadas para el régimen y gobierno del gremio de Fabricantes de Cera de esta Corte, aprobadas por el Real y Supremo Consejo de Castilla en 3 de julio de 1794, Madrid, Imprenta de la viuda de Villalpando, 1830, 20 pp., $4^{\circ}$. Ejemplar en Museo del Traje (Madrid), signatura FA-C17-41. 
Los datos hablan casi por sí solos. Solamente en dos periodos, durante la Guerra de la Independencia y el Trienio Liberal se imprimen más folletos que libros en la imprenta de Fermín Villalpando, con una proporción de 21 a 13 durante los años $1808-1814$ y de 41 a 26 entre 1820 y 1823 . La urgencia y presión de los sucesos exigió entonces la presentación de unos textos directamente involucrados en los acontecimientos a través de un medio producido con mayor rapidez y menor cuidado tipográfico, que iban a pasar muchas veces de mano en mano en los nuevos espacios públicos -el café, el club-, ligados a una lectura menos individualizada, que provoca el intercambio de opiniones y la discusión. La diferenciación de estos papeles según su función para todo el periodo de producción de la imprenta, nos ofrece las siguientes cifras: 45 folletos manifiestan un propósito polémico dentro del ámbito social y político; 13, una finalidad piadosa o litúrgica; 11, son textos directamente literarios; otros 11 ejercen una función informativa; 7 , muestran una finalidad educativa; 6 , desempeñan una función legal —desde ordenanzas y reglamentos a memoriales impresos-; 4 son piezas relativas a la disciplina eclesiástica y 2 poseen una función publicitaria en relación con la imprenta Villalpando. El que los folletos que cumplen una función asociada a lo religioso se limiten al $17 \%$, resulta significativo, pues nos va indicando la predominante orientación hacia lo laico de la imprenta de Fermín Villalpando.

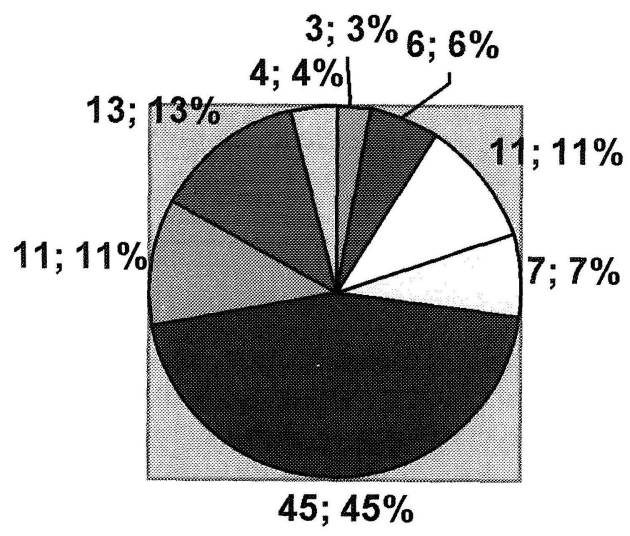

\begin{tabular}{|l|}
\hline$\square$ publicitaria \\
alegal \\
$\square$ informativa \\
$\square$ educativa \\
$\square$ polémica \\
$\square$ literaria \\
$\square$ piadosa \\
$\square$ disc. ecles.
\end{tabular}

Diferenciación de los folletos por su función

Distinguéndola según formatos, la producción de la imprenta Villalpando entre 1794 y 1830, nos proporciona las siguientes cifras y porcentajes: las obras en octavo son mayoría, 142 -el $46 \%$-; en cuarto se han impreso 122 obras -el $41 \%$-; en dozavo hay 29 obras -el $10 \%$-; en dieciseisavo, sólo 3 -un $1 \%$-; significativamente, los infolios son solamente 5 - un $2 \%$ - 


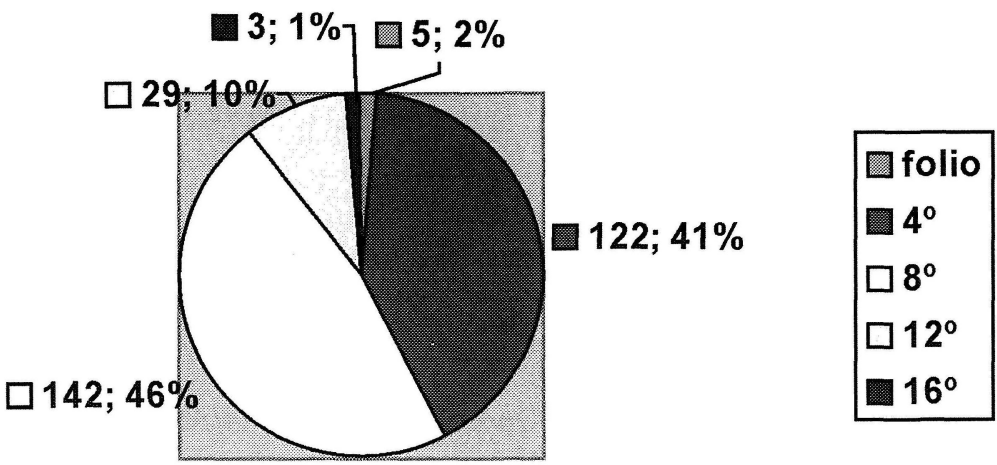

Producción de la imprenta Villalpando entre 1794-1830, según formatos

Los formatos menores $-8^{\circ}, 12^{\circ}, 16^{\circ}-$, ligados a las nuevas ideas, a la nueva sensibilidad, son predominantes. Son formatos portables, que pueden llevarse consigo en el paseo solitario, manifestando un tipo de lectura intensa. El octavo es también el formato del periódico, que pasa de mano en mano en los espacios de la nueva sociabilidad: el café, la tertulia y el club. Son formatos ligados a una cultura más conversacional, menos reverente hacia la autoridad, tanto cultural como política. El formato $4^{\circ}$ es en Villalpando el del libro de estudio, en que se presentan las nuevas aportaciones de las ciencias puras y las ciencias sociales. En la imprenta Villalpando, la presencia de los folios es completamente marginal, estando reservada a la publicación de memoriales y defensas legales por parte de particulares, de un interés muy restringido $^{28}$. En la imprenta Villalpando ha desaparecido el infolio como formato de la autoridad cultural.

Si pasamos a relacionar los diferentes formatos con el contexto políticosocial, observamos que los pequeños formatos son mayoritarios hasta el comienzo de la Guerra de la Independencia y durante el Trienio Liberal, y manifiestan una menor presencia durante los distintos periodos de represión fernandina. Su menor presencia durante los años de la Guerra de la Independencia podría explicarse por la práctica paralización de la producción durante los años 1809-1811.

${ }^{28}$ Así, por ejemplo, la Defensa legal que... Don Juan Favra Bernaldo de Quirós... abogado... hace contra Don Joseph Veladiez de la Bastida Bernaldo de Quirós... vecino de la ciudad de Guadalaxara y Don Joaquin Bernaldo de Quirós... en el pleyto que siguen sobre la tenuta y posesion de los mayorazgos fundados en la villa de Torrelaguna por Alonso Bernaldo de la Plaza n. 8..., Madrid, en la imprenta de Don Fermin Tadeo Villalpando, 1797, [1] + 16 hs., fol. Ejemplar en la Fundación Sánchez Maurandi (Mula), signatura R. 833. 


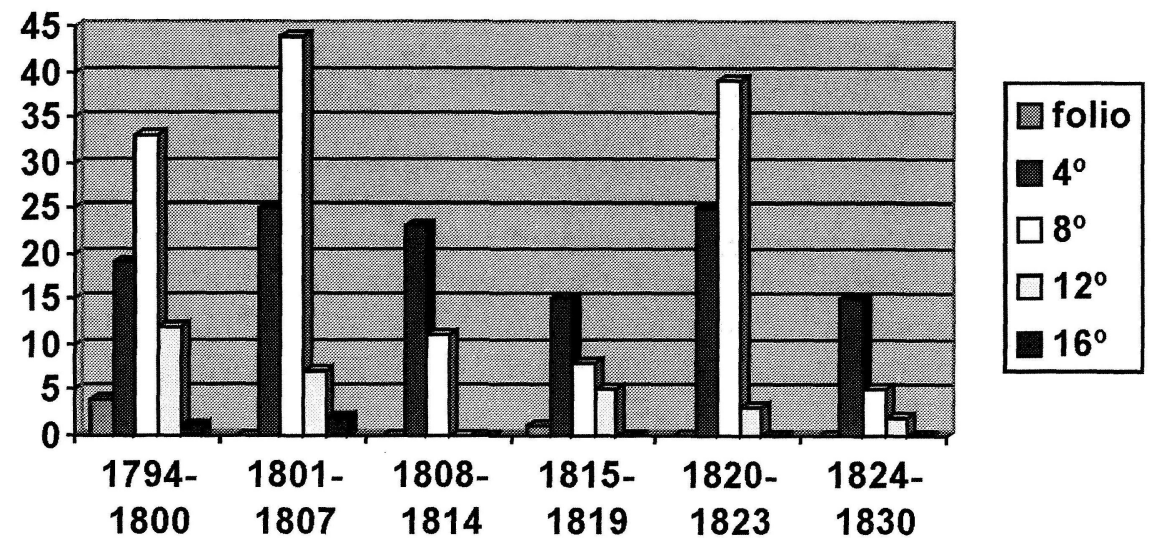

Producción de la imprenta Villalpando, según formatos, en relación con el contexto político

«En edición diferente, los libros dicen cosas distintas» escribió el poeta Juan Ramón Jiménez, impulsor de la renovación editorial y tipográfica que tuvo lugar en España en las primeras décadas del siglo XX, cita que gusta recordar hoy el poeta y editor Andrés Trapiello ${ }^{29}$. Un aspecto sobresaliente de la imprenta de Fermín Villalpando fue su intervención en la modificación del diseño de los libros en los años anteriores a la Guerra de la Independencia, en tanto que manifestación de un nuevo gusto, una nueva sensibilidad $\mathrm{y}$, asimismo, un nuevo modo de leer. Estamos haciendo referencia a sus cuidadas ediciones en octavo y dozavo, con portadas muy despejadas y limpias, con texto reducido al mínimo, en que el negro de los caracteres resalta sobre el blanco del papel. Son portadas clasicistas, pero no de un clasicismo radical a lo Bodoni, buscando más bien el buen gusto en su combinación de letras romanas, cursivas y caladas. Villalpando suele utilizar en su imprenta los tipos de letra y viñetas del grabador de punzones catalán Eudald Pradell (1721-1788), afincado en Madrid a mediados de los sesenta. De hecho, en 1795, al comienzo de su andadura editorial, publicó unas Muestras de los caractéres que tiene en su obrador Pedro Ifern, fundidor de esta Corte ${ }^{30}$, que

${ }^{29}$ Juan Ramón JimÉNEZ, Ideolojía (1897-1957). Metamorfosis, IV, Barcelona, Anthropos, 1990 , p. 382, n. $^{\circ} 2323$.

${ }_{30}$ Pedro IFERN, Muestras de los caractéres que tiene en su obrador Pedro Ifern, fundidor en esta Corte, [Madrid], En la imprenta de Fermin Thadeo Villalpando, Año MDCCXCV [1795], $8^{\circ}$. Ejemplar en BNM, signatura U-2305. A veces sus letrerías se denominan en los inventarios como las «del catalán», distiguiéndolas de las «de Gil», así por ejemplo en el inventario de la imprenta Ibarra de 1787, vid. J. Moll, «Dos inventarios de la imprenta de Joaquín Ibarra», De la imprenta al lector. Estudios sobre el libro español de los siglos XVI al XVIII, Madrid, Arco Libros, 1994, pp. 159-174. 
era el yerno de Pradell y fundía los tipos obtenidos con las matrices formadas con los punzones grabados por su suegro.

De este tipo de características ediciones que devienen imagen de marca, puede ser ejemplo la serie de comedias que Villalpando imprimió para Leandro Fernández de Moratín: La comedia nueva (1802), El barón (1803), La mojigata (1804) — reeditada en 1806-, El sí de las niñas (1805) - reeditada en 1806-, y su versión de La escuela de los maridos de Molière $(1812)^{31}$. Tengamos en cuenta que nos hallamos aquí ante libros, es decir, impresos para encuadernarse más o menos lujosamente con vistas a ser conservados en una biblioteca particular; no nos hallamos ante la usual comedia suelta en cuarto, que, en tanto que pliego suelto, es un folleto, al que como mucho se le proporciona una mera cubierta en papel de aguas. Mientras que estos libros se han impreso para ser manejados con cuidado y respeto en el gabinete, en el paseo o en la tertulia, las usuales comedias sueltas en cuarto, más utilitarias, pasaban de mano en mano. Muy ocasionalmente, Fermín Villalpando imprimió alguna de estas comedias sueltas en cuarto a doble columna, como es el caso de un conjunto de cinco comedias que imprimió para el librero Cerro en 1799 y 1800 , tres de Luciano Francisco Comella - Catalina Segunda en Cronstadt, La dama sutil y Las pelucas de las damas-, el Idomeneo de Eugenio de Tapia y El pintor fingido de Vicente Rodríguez de Arellano ${ }^{32}$. Estas comedias de surtido se vendían sueltas, en su puesto de la calle Alcalá y su tienda de la calle Cedaceros, al módico

${ }^{31}$ [Leandro FERnÁNDEZ DE MORATín], La comedia nueva. Comedia en dos actos, en prosa, Madrid, Imprenta de Villalpando, 1802, 94 pp., $8^{\circ}$. Ejemplar en BNM U-686.

-, El baron. Comedia en dos actos, en verso. Su autor Inarco Celenio, P. A., Madrid, en la Imprenta de Villalpando, 1803. 4 hs. + 134 pp., $8^{\circ}$. Ejemplares en BNM, signaturas $\mathrm{T}-14583$ y U-5233.

-, La mogigata. Comedia en tres actos, en verso. Su autor Inarco Celenio, Madrid, Villalpando, 1804, 180 pp., $8^{\circ}$. Ejemplares en BNM, signaturas T-9698 y U-683. Con reedición: La mogigata. Comedia en tres actos, en verso. Su autor Inarco Celenio P. A., Madrid, Imprenta de Villalpando, 1806, 179 pp., $8^{\circ}$. Ejemplar en BNM, T-21207.

—, El sí de las niñas. Comedia en tres actos, en prosa. Su autor Inarco Celenio, P. A., Madrid, Villalpando, 1805, 246 pp., $12^{\circ}$. Ejemplar en British Library, G-18135. Reeditado como El sí de las niñas. Comedia en tres actos, en prosa. Su autor Inarco Celenio P. A., Madrid, Villalpando, 1806, 144 pp., $12^{\circ}$. Ejemplar en Biblioteca Municipal de Madrid, 173-10.

MOLIÈRE, La escuela de los maridos. Comedia escrita en francés por Juan Bautista Molière, y traducida á nuestra lengua por Inarco Celenio P. A., Madrid, Imprenta de Villalpando, 1812, 128 pp., $8^{\circ}$. Ejemplar en BNM, signatura T-10541.

${ }^{32}$ Luciano Francisco Comella, Catalina Segunda en Cronstadt. Drama heroyco en dos actos. Por Don..., representado por la Compañía de Francisco Ramos, Madrid, Fermin Tadeo Villalpando-Se hallará en la librería de Cerro, 1799, 30 pp., 4º. Ejemplar en BNM, signatura T-632.

—, La Dama sutil. Comedia en dos actos. Por Don ... Representada por la Compañía de Francisco Ramos, Madrid, Fermin Tadeo Villalpando, año de 1799, 17 hs., $4^{\circ}$. Ejemplar en BNM, signaturas T-9135 y T-12760. 
precio de uno o dos reales, según se tratase de comedias de uno o varios actos.

Sin embargo, el primer trabajo de Fermín Villalpando para Leandro Fernández de Moratín había sido la impresión de su traducción del Hamlet de Shakespeare ${ }^{33}$ en 1798 . Moratín nombra al impresor en su diario en la entrada correspondiente al viernes 28 de septiembre: «Calles; chez Villalpando imprimeur; chez tía Teresica. / chez Mariquita Salmantina ex Saint Roc street, tactus, risimus; Calles; Scola Pia; cum Padre Juan chez Don Guillermo ex Puerta de Sol.» - curiosamente, el día anterior, había estado por la mañana «chez [Benito] Cano»- ${ }^{34}$. Para esta primera colaboración el formato escogido fue el cuarto, seguramente porque Moratín quiso incluir en la contraportada de la obra la estampa que había encargado en Roma al artista neomanierista romano Giuseppe Cades (1750-1799), al que el dramaturgo trató mucho entre marzo de 1794 y marzo de 1796, llegando a posar para él en repetidas ocasiones en noviembre y diciembre de 1795, pues le estaba pintando un retrato: «chez Cades, portrait» ${ }^{35}$. Con poca molestia, Moratín transportaría en su equipaje de vuelta la lámina de cobre grabada por el habitual colaborador de Cades Giovanni Battista Leonetti, estampándose la cantidad de estampas necesaria para la edición en el tórculo de un taller de estampación madrileño. Se trata de una estampa de calidad, como corresponde al diseño de uno de los principales artistas europeos de su tiempo, que en su juventud se había movido en el círculo del prerromántico suizo Fuseli y en la última década de su vida se mostró muy interesado en Miguel Ángel. Representa el encuentro de Hamlet con el fantasma de su padre en una no-

-, Las Pelucas de las Damas. Saynete por D. ..., representado por la compañia de Francisco Ramos, el dia 4 de Noviembre de 1799, Madrid, Fermin Tadeo Villalpando, 1799, 11 pp., $4^{\circ}$. Ejemplar en Instituto del Teatro (Barcelona), signatura 45383.

Eugenio DE TAPIA, Idomenéo. Drama trágico, con intervalos de música en un acto. Por D. E. T., Madrid, En la imprenta de D. Fermin Tadeo Villalpando, Año de 1799, 14 pp., $4^{\circ}$. Ejemplar en BNM, signatura T-24043.

Vicente RODRÍGUEZ DE ARELlANO, El pintor fingido. Comedia en tres actos por Don ... Representada por la Compañía de Luis Navarro, Madrid, Fermín Tadeo Villalpando, 1800,28 pp., $4^{\circ}$. Ejemplar en BNM, signatura T-5064.

${ }_{33}$ William ShAKESPEARE, Hamlet. Tragedia de Guillermo Shakespeare. Traducida $e$ ilustrada con la vida del autor y notas críticas por Inarco Celenio, P. A., Madrid, en la Oficina de Villalpando, 1798, 24 hs. +379 pp., $4^{\circ}$. Estampa dibujada por G. Cades y grabada por G.-B. Leonetti, talla dulce (buril y aguafuerte), 14,7 x 9,5 cm. Ejemplar en Palacio Real de Madrid, IX/6528.

${ }^{34}$ L. FERNÁNDEZ DE MORATín, Diario (mayo 1780-marzo 1808), editado por R. y M. Andioc, Madrid, Castalia, 1968, p. 209.

${ }^{35}$ En el cuaderno $8^{1}$ de su Viage a Italia, Moratín señala a Cades como modelo para el dibujo de entre los artistas residentes en Roma a mediados de los noventa: «los dibujos de Cades pasan, quando el quiere, por estudios del Guercino, de Julio Romano, de Andrea del Sarto y de los más famosos profesores antiguos», en L. FERNÁNDEZ DE Moratín, Viage a Italia, ed. de B. Tejerina, Madrid, Espasa Calpe, 1988, p. 584. 
che de luna. El fantasma, vestido de armadura, señala acusadoramente a su hijo, que, con la espada desenvainada, parece querer echarse atrás. Detrás del fantasma hay un denso paisaje boscoso; detrás de Hamlet, vemos las murallas de un castillo.

Entre 1794 y 1830, un buen número de las obras impresas en el taller de Fermín Villalpando incluyeron estampas calcográficas. Habituales colaboradores fueron los grabadores Simón Brieva, José Gómez de Navia, Esteban Boix y Blas Ametller, discípulos directos de Manuel Salvador Carmona en la Academia de San Fernando, de la que fue director para el grabado en dulce entre 1777 y 1820 . También algunos valencianos afincados en Madrid, como Miguel Gamborino, Francisco de Paula Martí y José Ximeno, algunos de ellos formados junto al grabador Manuel Monfort, director de grabado de la Academia de San Carlos de Valencia, que a mediados de los ochenta había sido nombrado por influjo de Pérez Bayer director de la Imprenta Real ${ }^{36}$. Entre las obras con un mayor número de ilustraciones cabe citar dos de divulgación científica y técnica, en que el grabado tiene un sentido directamente utilitario: el Compendio de la Historia Natural de Buffon (1802-1811), con un retrato y 90 estampas, que en algunos juegos se venden iluminadas, y el Semanario de Agricultura y Artes dirigido a los párrocos (1797-1808), editado por Juan Antonio Melón, que incluyó 25 estampas, sin contar con el frontispicio alegórico dibujado por Luis Paret y grabado por Ametller ${ }^{37}$. Como curiosidad, la estampa VIII, representando un carnero y un perro, que acompaña al número 126 del Semanario, correspondiente al 6 de junio de 1799, fue dibujada por Leandro Fernández de Moratín, íntimo de Melón ${ }^{38}$.

¿Qué autores publicó la imprenta Villalpando entre 1794 y 1830 ? En primer lugar, si distinguimos entre escritores españoles y extranjeros, veremos que los españoles son 183, frente a 67 extranjeros, lo que supone una proporción del 73 frente al $27 \%$. De los españoles, el $94 \%$ - es decir, 172-, son autores pertenecientes al siglo XVIII y las primeras décadas del siglo XIX, es decir contemporáneos en sentido amplio, frente a un escaso $6 \%$ de autores

${ }^{36}$ Vid. Maestros del grabado: siglo XVIII: la Real Academia de San Fernando, Madrid, Calcografía Nacional, 1991.

${ }^{37}$ La suscripción anual al Semanario costaba 75 reales. Los dos tomos anuales resultantes podían también adquirirse a la rústica al precio de 22 reales, o encuadernados a 24 reales cada uno. El periódico, que alcanzó los 599 números, salía los jueves y según los editores tendría una extensión de dos pliegos, sin contar las estampas. E. Larriba señala cómo, en ocasiones, se realizan tiradas paralelas de determinados números, con estampaciones de mayor o menor calidad, a fin de satisfacer el gusto más exquisito de sus lectores más refinados. Vid. E. LARRIBA, «L'art au service de la divulgation scientifique: le rôle des gravures dans le Semanario de Agricultura y Artes dirigido a los Párrocos (17971808)», El Argonauta Español 2 (2005), en http://argonauta.imageson.org/document57.html

${ }^{38}$ L. FERnÁNDEZ DE MORATÍn, Diario, ob. cit., p. 218; entrada correspondiente al 4 de abril de 1799: «ici Melón; cum il chez il, diseñar mouton». Vid. E. LARRIBA, art. cit., p. 14. 
españoles que podríamos denominar «clásicos». ¿De qué clásicos españoles se trata? Francisco de Quevedo ${ }^{39}$ (1794 y 1798), Miguel de Cervantes ${ }^{40}$ (1799) y el Inca Garcilaso ${ }^{41}$ (1800 y 1803), son publicados en dos ocasiones distintas. Ven la luz una única vez en sus prensas Jorge de Montemayor (1795), Lope de $\mathrm{Vega}^{42}$ (1796), el marqués de Santillana acompañado de Jorge Manrique $^{43}$ (1799), Jerónimo de Ripalda ${ }^{44}$ (1803) y Alonso Fernández de Avellaneda $^{45}$ (1805). Significativamente, de Cervantes publica las Novelas ejemplares y los Trabajos de Persiles y Sigismunda, ambas en dozavo, y nunca El Quijote, prefiriendo sacar la continuación de Avellaneda, menos ofertada por esas décadas. Se presentan también en dozavo los seis volúmenes de las Obras jocosas y las Poesías escogidas de Quevedo (1798); formato escogido para los Proverbios de Mendoza junto con las Coplas de Manrique. En dieciseisavo se imprimen los cuatro volúmenes de la Historia de la Florida del Inca Garcilaso. Las restantes ediciones de estos clásicos

${ }^{39}$ Francisco DE QUEVEdo Y VILlegas, Obras escogidas de... Francisco de Quevedo Villegas, En Madrid, por Fermín Tadeo Villalpando: se hallarán en la librería de Castillo, frente a san Felipe el Real, 1794, 2 vols., $8^{\circ}$. Ejemplar en Universidad Pontificia de Comillas (Cantoblanco), signatura XVIII-8337.

-, Obras jocosas del célebre don..., Madrid, Imprenta de Villalpando, 1798, 6 vols., $12^{\circ}$. Los vols. III-VI bajo el título Poesías escogidas de don Francisco de Quevedo y Villegas. Ejemplar en Biblioteca Regional de Madrid, signatura A-455 (I-VI).

40 Miguel DE CERVANTES, Novelas ejemplares, Madrid, Imprenta de Villalpando, 1799, 3 vols., $12^{\circ}$. Ejemplar en British Library, signatura 12490.aaa.19.

-, Trabajos de Persiles y Sigismunda. Historia setentrional, Madrid, por D. Fermin Villalpando, 1799, 2 vols., $12^{\circ}$. Ejemplar en Biblioteca General de Navarra (Pamplona), signatura 7-1/184-185.

${ }^{41}$ Garcilaso DE LA Vega, Historia general del Perú ó Comentarios reales de los Incas por el Inca Garcilaso de la Vega. Nueva edición, Madrid, imprenta de Villalpando, 18001801, 13 vols., $8^{\circ}$. Ejemplar en RAH, 3/8046.

- Historia de la Florida por El inca Garcilaso de la Vega, Madrid, Imprenta de Villalpando, 1803, 4 vols., $16^{\circ}$. Ejemplar en RAH, 3/8042/8045.

${ }^{42}$ LOPE DE VEGA, Poesías escogidas... con un discurso sobre la oda por Marmontel, Madrid, en la Imprenta de Villalpando, 1796, LXIV + 368 pp., $8^{\circ}$. Ejemplar en Biblioteca Valenciana, signatura LL.G./2744.

${ }^{43}$ Iñigo LóPEZ DE MENDOZA, Proverbios de don Iñigo López de Mendoza, marqués de Santillana. Y las coplas de D. Jorge Manrique, todo con sus glosas, Madrid, por D. Fermin Villalpando, 1799, XXX +432 pp., 12 ${ }^{\circ}$. Ejemplar en Biblioteca Histórica Municipal (Madrid), signatura Par/494.

${ }^{44}$ Gerónimo DE RIPALDA, Catecismo y exposición breve de la doctrina christiana compuesto por Gerónimo de Ripalda de la Compañía de Jesús; añadido el orden de ayudar a misa, quatro tratados muy devotos y otras oraciones muy provechosas y útiles para la salud espiritual por Ignacio Martinez de la misma Compañía, Madrid, Imprenta de Villalpando; se hallará en la Librería de Saturnino Ramon Fernandez, 1803, [8] + 156 pp., $8^{\circ}$. Ejemplar en Palacio Real de Madrid, IX/2 89.

${ }_{45}$ Alonso Fernández de Avellaneda, Vida y hechos del ingenioso hidalgo $D$. Quixote de la Mancha. Contienen su cuarta salida, y la quinta parte de sus aventuras, Madrid, Imprenta de Villalpando, 1805, 2 vols., $8^{\circ}$. Ejemplar en RAH, 14/4363-4364. 
aparecen en octavo. Todo ello nos indica que se pretende la portabilidad de estos títulos, reflejo de una lectura intensiva. Tiene su interés el que las Poesías escogidas de Lope se publiquen conjuntamente con un discurso sobre la oda de Marmontel, signo de que ya no existe esa contundente oposición entre barroquismo y neoclasicismo de las décadas siguientes a la aparición de la Poética de Luzán y de que está teniendo lugar una cierta rehabilitación de determinados dramaturgos y poetas del Barroco.

Volviendo la vista a los 172 autores españoles contemporáneos, sólo 41 de ellos, correspondientes a un $24 \%$, son eclesiásticos, frente a 131 laicos, que suponen el $76 \%$. Frente a la inclusión, por puro oportunismo editorial, en un periodo político y empresarial muy concreto, de un fray Diego José de Cádiz, estandarte del más rancio tradicionalismo, componen mayoría aquellos clérigos que representan las distintas vertientes de la participación a nivel individual de los eclesiáșticos españoles en una renovación de ideas y sensibilidades orientada a las Luces o el Liberalismo. Es el caso, entre otros, de fray Juan Fernández de Rojas ${ }^{46}$, Pedro Estala y Juan Antonio Melón, Francisco Martínez Marina, el Trigueros del Teatro español burlesco ${ }^{47}$, el exjesuita Hervás y Panduro instructor de los sordomudos ${ }^{48}$ o el Isla traductor de Gil Blas $^{49}$.

Entre los autores españoles contemporáneos, no parece casual la abundante presencia editorial de uno de los núcleos intelectuales y literarios más activos en el periodo de entre siglos, el de los amigos y literatos afines a Leandro Fernández de Moratín -Pedro Estala, Juan Antonio Melón, Juan Pablo Forner y Agustín García de Arrieta-, favorecidos en repetidas ocasiones por el gobierno de Manuel Godoy, al que prodigan sus alabanzas,

${ }^{46}$ [Fray Juan FERnÁNDEZ DE RoJAS y Juan Antonio DE IZA ZAMACOLA], Libro de moda ó ensayo de la historia de los currutacos, pirracas, y madamitas del nuevo cuño. Escrito por un filósofo currutaco, y aumentado nuevamente por un señorito Pirracas, Madrid, En la Imprenta de Fermin Villalpando, Año de 1795, XXXIV + 135 pp., $12^{\circ}$. Ejemplar en BNM, signatura R-14639.

47 [Candido María Trigueros], Teatro español burlesco o Quixote de los Teatros. Por el Maestro Crispín Caramillo. Cum notis variorum, Madrid, Imprenta de Villalpando, 1802, $24+160$ pp., $8^{\circ}$. Ejemplar en BNM, T-32077.

${ }^{48}$ Lorenzo HERVÁS Y PANDURO, Escuela española de sordomudos ó arte para enseñarles á escribir y hablar el idioma español, en Madrid, Imprenta Real-en la Imprenta de Fermín Villalpando, 1795, 2 vols., $4^{\circ}$. Vol. II: 3 hojas +376 pp., 5 estampas plegadas. Ejemplar en Palacio Real de Madrid, signatura VIII/5490 (para vol. II).

- Catecismo de Doctrina christiana para instrucción de los sordomudos. Dividido en quatro diálogos, de los que el quarto contiene la Doctrina christiana, y los tres primeros su introducción a ella. Por el abate D. ..., Madrid, Villalpando, 1796, 3 hs., + 182 pp., $12^{\circ}$. Ejemplar en BNM, signatura 3-43429.

${ }^{49}$ Alain-René LE SAGE, Aventuras de Gil Blas de Santillana restituidas del francés de Mr. Le Sage al castellano por el P. F. de I., Madrid, Imprenta de Villalpando, 1799, 5 vols., $12^{\circ}$. Ejemplar en Facultad de Teología del Norte de España (Burgos), signatura Xm 200/1-5. Obra reeditada por Villalpando en 1800 y 1805. 
mostrándose siempre afines a su política ${ }^{50}$. Forner, que en julio de 1796 fue nombrado fiscal del Consejo de Castilla, publicó ese mismo año en la imprenta Villalpando su comedia La escuela de la amistad, dedicada a Luis Godoy, hermano del favorito, y su poema La Paz. Canto heroyco. Al Excelentísimo Señor Príncipe de la Paz ${ }^{51}$, en que la adulación comienza ya en la tipografía de la portada. El Semanario de Agricultura y Artes, criatura de Godoy, estuvo al cuidado directo del presbítero Melón hasta enero de 1805, año en que fue designado juez privativo de imprentas, dejando la edición del periódico en manos de un equipo de profesores del Real Jardín Botánico: Francisco Antonio Zea, Claudio Boutelou y Simón de Rojas Clemente y Rubio. Estos dos últimos, junto con Esteban, hermano de Claudio Boutelou, tras haber sido pensionados por el gobierno para completar su formación en Europa, publican habitualmente en las prensas de Villalpando ${ }^{52}$. Por todo ello,

${ }^{50}$ Para la discrepacia política y literaria entre moratinistas y quintanistas, y su diferente actitud ante el poder, véase J. CHECA BELTRÁN, «Debate literario y política», en J. Álvarez BARrientos (ed.), Se hicieron literatos para ser políticos. Cultura y política en la España de Carlos IV y Fernando VII, Madrid, Biblioteca Nueva-Servicio de Publicaciones de la Universidad de Cádiz, 2004, pp. 147-165. Sobre el grupo en torno a Moratín, puede consultarse también J. PÉREZ MAGALlón, «Escritores y amigos: el caso de Moratín y Melón», en G. CARNERo, I.-J. LóPEZ y E. RubIO (eds.), Ideas en sus paisajes. Homenaje al profesor Russell P. Sebold, Alicante, Univesidad de Alicante, 1999, pp. 339-351. Además de sus comedias, Moratín también publica en esta oficina su poema La sombra de Nelson. Por Inarco Celenio P. A., Madrid, Villalpando, 1805, 8 pp., $8^{\circ}$. Ejemplares en BNM, signaturas V. E. 498 (13) y 577 (11). Para Godoy y su imagen pública, véase el libro, sugerentemente ilustrado, de I. ROSE DE VIEJO, E. LA PARRA y Enrique GIMÉNEZ LÓPEZ, La imagen de Manuel Godoy, Junta de Extremadura, 2001.

${ }^{51}$ Juan Pablo Forner, La escuela de la amistad ó el filósofo enamorado. Comedia. Precede una apología del vulgo con relación á la poesía dramática, Madrid, en la imprenta de Fermín Villalpando, año de 1796, XXXVIII + 141 pp., $8^{\circ}$. Ejemplar en BNM 7-78979.

-, La Paz. Canto heroyco. Al Exc. ${ }^{m o}$ Señor Príncipe de la Paz, Madrid, En la Oficina de Villalpando, 1796, 13 hs. + XXXIX pp. +1 hoja de erratas, $4^{\circ}$. Ejemplares en BNM 2-16484 y V. E. $381(24)$.

52 Claudio Boutelou, Tratado de la huerta o método de cultivar toda clase de hortalizas, Madrid, Villalpando, 1801, 400 pp., $4^{\circ}$. Ejemplar en Academia de Medicina de Madrid, signatura 5-2-13. Reeditado por Villalpando en 1813.

-, Tratado de las flores en que se especifica el método de cultivar las que viven para adorno de los jardines por D. ... Segundo profesor de botánica y jardinería mayor del Real Jardín Botánico de Madrid y por D. Esteban Boutelou, Jardinero Mayor en el Real sitio de Aranjuez. Individuos de mérito en la clase de Agricultura de la Real Sociedad Económica de Madrid y Socios de la de Historia Natural de Paris, Madrid, En la Imprenta de Villalpando, año de 1804, VIII + 424 pp., $4^{\circ}$. Ejemplar en BNM, signatura 1-42769. Reeditado por Villalpando en 1827.

-, Memoria sobre el cultivo de la vid en Sanlúcar de Barrameda, Madrid, Villalpando, 1807, 160 pp. + 1 lám., $23 \mathrm{~cm}$. Ejemplares de distintas emisiones, con variación tipográfica y de contenido en la introducción, en Palacio Real de Madrid, signaturas I/F/497 y IX/7768. 
el impresor, que es objeto de la confianza y el respaldo de todos estos hombres de letras, puede contarse como un beneficiario más de la política editorial promovida y protegida por el Príncipe de la Paz.

Pasando ahora a los autores extranjeros que salieron de la imprenta en el periodo 1794-1830, los contemporáneos son 60 , que corresponden al $90 \%$ del total, frente a sólo 7 de otras épocas, que suponen un $10 \%$. Estos escasos autores no contemporáneos son san Pablo, cuyas Epístolas se traducen y anotan en 1796, W. Shakespeare, en la versión del Hamlet por Moratín (1798), el clérigo jansenista Pierre Nicole del que se traduce en 1800 el Arte de vivir en paz con los hombres, el Molière de La escuela de los maridos traducido asimismo por Moratín (1812), el san Buenaventura de la Devoción a María Santísima de los Dolores (1815), sor Luisa de la Misericordia, en el mundo duquesa de La Vallière, de la que se traducen sus Sentimientos, afectos y conversión de un alma a Dios, sobre los salmos L y CII (1816) y, ya en el Trienio Liberal, el Demóstenes de la Oracion en defensa suya acerca de la Corona ${ }^{53}$.

Esteban BOUTELOU, Experimentos y observaciones agronómicas sobre la cebada ramosa hechas en los reales jardines de Aranjuez, Madrid, Villalpando, 1806, 28 pp., $4^{\circ}$. Citado por Palau, 34103.

Simón DE ROJAS CLEMENTE y RUBIO, Ensayo sobre las variedades de la vid común que vegetan en Andalucía, con un índice etimológico y tres listas de plantas en que se caracterizan varias especies nuevas. Por Don Simón de Rojas Clemente y Rubio, Bibliotecario del Real Jardín Botánico de Madrid, individuo de las Reales Sociedades Económicas de Granada y Sanlúcar de Barrameda, \&c. De orden Superior, Madrid, Imprenta de Villalpando, 1807, XVIII + 324 pp., $4^{\circ}$. Ejemplar en Jardín Botánico de Madrid, signatura 11-127.

Para C. BOUTELOU y S. DE ROJAS, vid. la introducción a la antología de E. LARRIBA y G. Dufour, El Semanario de Agricultura y Artes dirigido a los Párrocos (1797-1808), Madrid, Ámbito, 1997.

${ }^{53}$ San Pablo, Epístolas de San Pablo Apóstol, traducidas de la Vulgata, e ilustradas con notas por D. Francisco Ximenez, Madrid, Villalpando, 1796, XVI + 528 pp., $8^{\circ}$. Ejemplar en Facultad de Letras (Madrid), signatura 6151.

Pierre NICOLE, Arte de vivir en paz con los hombres. Extractado de los Ensayos de Moral del célebre Pedro Nicole, por el Ilmo. Sr. Don Fr. Antonio de Padua, actual obispo de Marañón. Y traducido al castellano por D. A. G. M. F. [Arias Gonzalo de Mendoza y Francia], Madrid, Villalpando, 1800, 4 hs. +254 pp., $12^{\circ}$. Ejemplar en BNM, signatura 3-20823.

San Buenaventura, Devoción a María Santísima de los Dolores que en forma de oficio divino compuso en latín... San Buenaventura, Madrid, [Imp. de Villalpando], 1815, 133 pp., $12^{\circ}$. Ejemplar en BNM, signatura V.E./613-38.

SOR LUISA DE LA MISERICORDIA, Sentimientos, afectos y conversión de un alma a Dios, sobre los salmos L y CII. Con reflexiones cristianas sobre nuestra flaqueza. Obra traducida de la que compuso en lengua francesa Sor Luisa de la Misericordia, por Miguel Copin, Madrid, Imprenta de Villalpando: se hallará en la Librería de la Viuda de Ramos, 1816, [4] + 268 pp., $4^{\circ}$. Ejemplar en BNM, 2-28925.

DEMÓSTENES, Oracion de Demostenes en defensa suya acerca de la Corona traducida del griego al español por J.F.V.J.D.M., Madrid, Imprenta de Villalpando, 1820, 211 pp., $8^{\circ}$. Ejemplar en Fundación Universitaria Española (Madrid), signatura SL.VII/839. 
Las distribución de estas traducciones al castellano según sus lenguas de origen viene a ser como sigue: del francés proceden 49 -el $74 \%$ - del italiano 7 -el $11 \%$-, del portugués 4 -el $6 \%$-, del inglés y el latín se traducen 3 obras, correspondientes, respectivamente a un $4 \%$ cada una, y del griego se traduce una sola obra -el $1 \%$ -
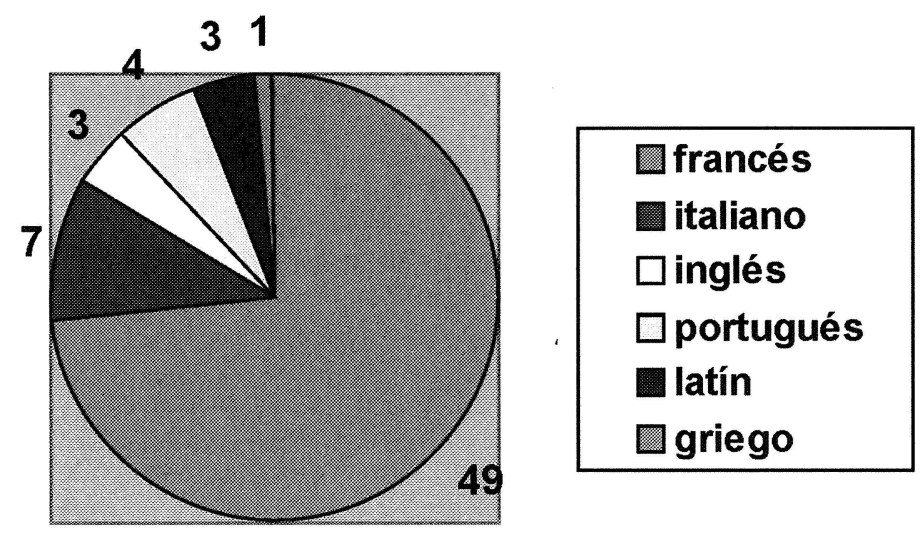

Traducciones publicadas por Villalpando en el periodo 1794-1830

Entre los traductores-editores que dieron a luz sus versiones en la imprenta de Villalpando cabe mencionar entre los más activos, además del emprendedor y laborioso Pedro Estala, a Arias Gonzalo de Mendoza, alcalde constitucional de Madrid en 1822, que entre 1794 y 1804 sacó cuatro obras de inclinación jansenista ${ }^{54}$, entre ellas la ya mencionada de Pierre Nicole; a Juan Sánchez Rivera y Ramón de Salas, que durante el Trienio publicaron relevantes obras de Filangieri, Say, Bentham y Destutt de Tracy, contribuyendo a poner al día a sus compatriotas por lo que respecta a las ciencias sociales; a los médicos Joaquín Serrano Manzano, Antonio Lavedán y Antonio Saviñón,

${ }^{54}$ Disertación apologética del Estado religioso, compuesta en francés por dos jurisconsultos del Parlamento de París. Traducido al castellano por Don Arias Gonzalo de Mendoza, Madrid, Fermin Thadeo Villalpando, 1794, 331 pp., $4^{\circ}$. Ejemplar en Palacio Real de Madrid, signatura X/488.

Claude Emmanuel JosePh PIERRE, MARQuÉs DE PASTORET, Moyses considerado como legislador y moralista... traducido y adicionado con varias notas por D. Arias Gonzalo de Mendoza y Francia, Madrid, en la imprenta de D. Fermin Tadeo Villalpando, 1798, 2 vols., $4^{\circ}$. Ejemplar en Biblioteca de Ciencias Sociales y Jurídicas, Universidad Carlos III (Madrid), signatura FA/1013.

Conferencias eclesiásticas de la diócesis de Angers, celebradas de orden de los Señores Obispos de aquella diocesis. Traducidas por D. Arias Gonzalo de Mendoza, Madrid, Fermin Villalpando, 1804-1807, 5 vols., $4^{\circ}$. Ejemplar en Monasterio de San Lorenzo del Escorial, 47-II-28/31. 
que vertieron al español importantes obras de su facultad ${ }^{55}$; al teatino Francisco Vázquez Girón, traductor del portugués Almeida en 1802 y $1806^{56}$; al agustino José de la Canal, traductor en 1807 del Catecismo para uso de todas las Iglesias del Imperio francés y de Merault en $1825^{57}$; y, ya dentro del cam-

55 John BRown, Errores y perjuicios del sistema espasmódico del doctor Cullen. Descubiertos y demostrados por el Dr. Juan Brown, presidente que fue de la Sociedad Médica de Edinburgo. Traducidos del Italiano... por el Dr. D. Joaquin Serrano Manzano, Médico del Real Colegio de esta Corte, Madrid, Imprenta Villalpando, 1796, CX + 208 $+[4]$ pp., $8^{\circ}$. Ejemplar en Universidad de Valencia, Facultad de Medicina, signatura D/ 102 .

William Rowley, Obras del célebre Guillermo Rowley... Traducidas del inglés por D. Joaquín Serrano y Manzano, Madrid, Imprenta de Villalpando, 1796-1798, 4 vols., $8^{\circ}$. Ejemplar en BNM, signatura 2-65547/50.

Johann FRIEDRICH FRITZE, Compendio sobre las enfermedades venereas del doctor Juan Federico Fritze; traducido al toscano por Juan Bautista Monteggia; y de este al castellano con notas por Antonio Lavedan, Madrid, Libreria de Gomez-Imprenta de Villalpando, 1804, XVI + $214+[2]$ hojas, $4^{\circ}$. Ejemplar en Real Academia de Medicina, signatura 24-1 Biblioteca 13.

Josef Jacob VON PLENCK, Farmacología chirúrgica o Ciencia de medicamentos externos e internos... Por José Jacobo Plenck... Segunda edición corregida y aumentada por Antonio Lavedán, Madrid, Villalpando, 1805,4 hs. + 568 pp., $4^{\circ}$. Ejemplar en BNM, 245292. Esta obra fue reeditada en 1819.

-, Toxicología, o doctrina de venenos y sus antídotos. Por José Jacobo Plenck. Traducido del latín al castellano, de la última edición, y aumentado por el Doctor D. Antonio Lavedán, Madrid, Fermín Villalpando, 1816, 4 hs. +299 pp. +2 hs., $4^{\circ}$. Ejemplar en BNM, signatura 1-12126.

Claude BALME, Consideraciones clínicas sobre las recaídas en las enfermedades, por el Doctor Balme. Traducidas del francés por el Dr. D. Antonio Lavedan..., Madrid, Villalpando, 1807, 4 hs. + 321 pp., $8^{\circ}$. Ejemplar en BNM, signatura 1-14331.

William BuCHAN, El conservador de la salud de las madres y de los niños, de William Buchan... Traducido del inglés por Thomas Duverne de Praille... y al español por D. A. $S$. [Antonio de Saviñón], Madrid, Villalpando, 1808, XVI + 432 pp., $8^{\circ}$. Ejemplar en Biblioteca Pública de Gijón, Res. 76-149.

${ }_{56}$ Teodoro DE AlmeIDA, Armonía de la Razón y de la Religión ó Respuestas Filosóficas a los argumentos de los Incrédulos: Dividida en dos tomos. Obra escrita en portugués por el P. Don Teodoro de Almeida... Traducida al castellano y aumentada con varias Notas por el Padre Don Francisco Vázquez, clérigo regular de San Cayetano, letor de Teología..., Madrid, en la Imprenta de Villalpando, 1802, 2 vols., $8^{\circ}$. Ejemplar en BNM, signatura 6-i-2812.

—, El Hombre Feliz, independiente del Mundo y de la Fortuna, ó Arte de vivir contento en todos los trabajos de la vida. Obra escrita en portugués por el P. D. Teodoro de Almeyda... Nueva traduccion mejorada en el estilo y en los versos por el Padre Don Francisco Vázquez. Clérigo reglar. Con las notas del autor y adornada con 25 estampas, Madrid, Imprenta de Villalpando, 1806, 4 vols., $8^{\circ}$. Ejemplar en BNM, signatura 3-24753/56.

${ }^{57}$ Catecismo para uso de todas las Iglesias del Imperio francés aprobado por el Cardenal Caprara, Legado de la Santa Sede y mandado publicar por el Emperador Napoleón, Madrid, Villalpando, 1807, XXXII + 222 pp., $8^{\circ}$. Ejemplar en BNM, signatura R-60402.

Atanase RENÉ MERAULT, Los apologistas o la religión cristiana probada por sus enemigos como amigos. Continuación de los apologistas involuntarios. Por M. Merault...; 
po de la bellas letras, las traducciones de narrativa debidas a Baltasar Driguet - su traducción de las Jornadas divertidas de madama de Gomez (1797) y de la Vida y persecuciones de Federico, barón de Trenck (1799) ${ }^{58}$ - , y las de Shakespeare y Molière debidas a Moratín.

Manifestación del sesgo modernizante de la imprenta Villalpando es el hecho de que a todo lo largo de su trayectoria, sólo produjese tres obras en latín, totalizando 10 vols.: las Intitutiones medicae de Hermann Boerhaave (1668-1738), editadas por Juan Bautista Soldevilla (1796-1801), los Institutionum Canonicarum Libri IV de Giovanni Devoti (1801-1802) y las jansenistas Institutiones theologiae de Joseph Valla (1821) ${ }^{59}$. A estas alturas, las ciencias modernas se publican ya mayoritariamente en castellano y el latín sólo es el refugio del derecho canónico y la teología. Se da también un caso, de texto mezclado de castellano y latín - las Definiciones latinas pertenecientes a los sacramentos del dominico Francisco Lárraga (1801), reeditadísmo manual de confesores corregido por Santos y Grosín-, y otro de texto paralelo en castellano y francés, el Nuevo método para enseñar la geogra-

traducida por el P.M.F. José de la Canal, Madrid, Imprenta de don Fermín Villalpando, 1825, XXXII +400 pp., $8^{\circ}$. Ejemplar en Facultad de Teología del Norte de España (Burgos), signatura IV:58-92.

${ }_{58}$ Madeleine Angelique DE GóMEZ, Jornadas divertidas, políticas sentencias y hechos memorables de los reyes y héroes de la antigüedad escritas por la Séneca del siglo XVII Madama de Gomez; traducidas del frances por don Baltasar Driguet, y adornadas con cinco láminas finas..., Madrid, Imprenta de Villalpando, tomos VII y VIII, 1797, $8^{\circ}$. Ejemplar en Fundación Universitaria Española (Madrid), signatura LIT2/995(1). Obra reeditada por Villalpando en 1806. Vid. M.-J. García Garrosa, «Días alegres, de Gaspar Zavala y Zamora: recuperación de una obra perdida. (I) Historia editorial», Dieciocho 26 (2003), pp. 199-222.

BARÓN DE TRENCK, Vida y persecuciones de Federico, barón de Trenck, escrita por él mismo. Traducida del aleman por el señor baron de $B^{* * *}$ y puesta en castellano por D. Baltasar Driguet, Madrid, Imprenta de Villalpando, 1799, 2 vols. I: XXVIII +226 pp. II: 235 pp., $8^{\circ}$. Biblioteca Complutense de la Compañía de Jesús de la Provincia de Toledo (Alcalá de Henares), signatura HUM/403. Reeditada por Villalpando en 1802.

${ }^{59}$ Hermann BoERHAAVE, Hermanni Boerhaave Institutiones medicae: pars I [-II]... Editionem istam curavit et auxit Joannes Baptista Soldevilla, Matriti, ex typographia Villalpandea, 1796-1797, 2 vols., $8^{\circ}$. Estos dos vols. son continuados por Hermanni Boerhaavii Aphorismi de cognoscendis et curandis morbis. Editionem istam curavit, et auxit Ioannes Baptista Soldevilla..., Matriti, ex typographia Villalpandea, 1798-1801, 2 vols., $8^{\circ}$. Ejemplar en Palacio Real de Madrid, signatura IX/751-IX/754.

Giovanni DevotI, Joannis Devoti Dei et apostolicae sedis gratia Episcopi Ananiensis Institutionum Canonicarum Libri IV, Matriti, ex Typographia de Villalpando, 1801-1802, 4 vols., $8^{\circ}$. Ejemplar en Biblioteca Complutense de la Compañía de Jesús de la Provincia de Toledo (Alcalá de Henares), signatura DER/467-468.

Joseph VALLA, Institutiones theologiae... auctoritate D.D. Archiepiscopi Lugdunensis ad usum scholarum suae diocesis editae, Matriti, ex typographia Firmini à Villalpandoex typographia Aguado et Societatis-ex typographia Leonardi à Nuñez, 1821, 6 vols., $8^{\circ}$. Sólo los dos primeros vols. se imprimieron en la oficina de Villalpando. Ejemplar en Facultad de Teología del Norte de España (Burgos), signatura IV:10-54/59. 
fía a los niños escrito en portugués y francés por Theodoro de Almeida $(1819)^{60}$.

Clasificando por materias la producción de la imprenta Villalpando a lo largo de sus tres décadas y media de actividad, sin olvidar precavernos acerca del natural solapamiento temático de algunas de estas obras, obtenemos las siguientes cifras y porcentajes. Advertimos que hemos considerado aquí también las reediciones. Con 62 obras, la literatura es la materia más publicada, alcanzando el $20 \%$; las ciencias puras y aplicadas, con 58 obras, suponen el $19 \%$; las ciencias sociales, el derecho y aquellas obras que desarrollan algún aspecto de la aplicación cotidiana de las leyes son 54, es decir, un $18 \%$; las de contenido político, con 54 obras, suponen otro $18 \%$; la religión está representada con 53 obras, reuniendo asimismo un $18 \%$; las obras de propósito educativo son 11 , lo que representa un $4 \%$; 7 , las de contenido filosófico, con un $2 \%$; finalmente, las obras relacionadas con el negocio de la imprenta son 2 , apenas un $1 \%$. Estos porcentajes podrían dar la engañosa impresión de una diversificación armónica de la producción entre 1794 y 1830 para las cinco áreas temáticas principales. Nada más lejos de la realidad, según se nos hace evidente, si tenemos en cuenta el contexto político.

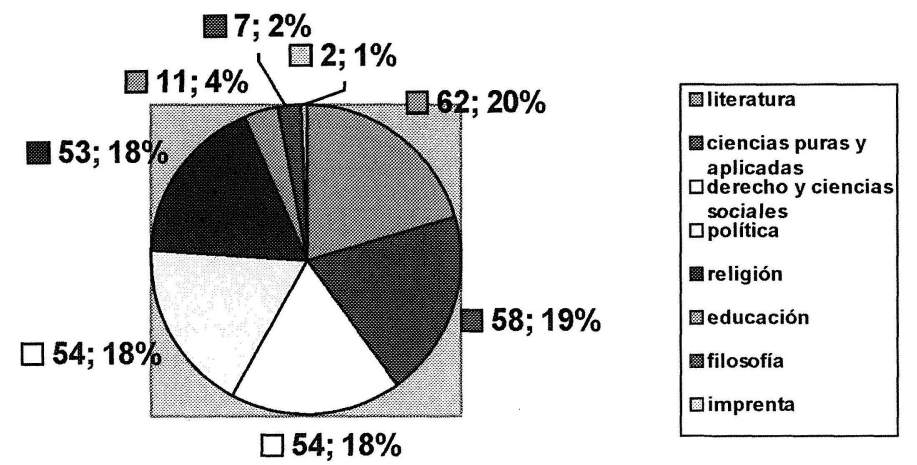

Diferenciación por materias de la producción de Villalpando para el periodo 1794-1830 (incluyendo reediciones)

${ }^{60}$ Francisco LÁRraga, Definiciones latinas pertenecientes a los sacramentos de la nueva ley, por el P. M. Fr. Francisco Larraga según Don Francisco Santos y Grosin, en su prontuario de Teología Moral. Y puestas en idioma castellano, y en forma de diálogo, e ilustradas con varias adiciones y exemplos muy claros también en castellano para el mayor alivio y adelantamiento de todos los profesores y en especial de los principiantes $y$ ordenados. Su autor A.B.C., Madrid, Villalpando, 1801, 75 pp. +1 hoja, $8^{\circ}$. Ejemplar en BNM, signatura V. E. caja 584 (22).

Teodoro DE ALMEIDA, Nuevo método para enseñar la geografía a los niños escrito en portugués y francés por Theodoro de Almeida; puesto en castellano... por Fernando Romero de Leis, Madrid, [Imprenta de Fermín Villalpando], 1819, 210 pp., 4º Ejemplar en BNM, signatura 2/47393. 
Descubrimos entonces que la literatura es sólo mayoritaria en los años 1794-1800, en que le corresponden 31 obras, para ser sustituida por las ciencias puras y aplicadas entre 1801-1807, en que se imprimen 29 obras pertenecientes a esta materia - frente a 19 literarias-. Durante la Guerra de la Independencia y el comienzo de la restauración absolutista fernandina, entre 1808-1814, es la política, con 17 obras, el sector más ofertado. Entre 1815 y 1819 , años de significativa recesión y debilidad en el negocio, comparten relativa primacía la religión y las ciencias puras y aplicadas, materias que dan a luz unas escuálidas 7 obras, respectivamente. Los años del Trienio Constitucional traen consigo un nuevo aumento de la producción de la mano del tirón que supone el renovado interés del público por la política y las afines ciencias sociales, representadas por 31 y 15 obras. Las obras de temática religiosa, con 14 obras, están bien representadas dentro de la producción del Trienio y, sin duda, ofrecieron a Villalpando la posibilidad de diversificar ideológicamente la producción, adquiriendo un nuevo sector de público asociado al conservadurismo sociológico que pudiera facilitar su supervivencia empresarial en caso de una nueva restauración del absolutismo. Tras la fractura política, se confirma la intensidad de la crisis en el negocio en los años 1824-1830, que tienen como endebles materias puntales el derecho y las ciencias sociales, por un lado, y las ciencias puras y aplicadas por otro, con unas escasas 8 y 6 obras. Recordemos que dentro de este último periodo de actividad de la imprenta Villalpando, los años 1829 y 1830, ya bajo el sello de la viuda de Villalpando, suponen un relativo incremento de la producción, en que son las ciencias sociales y el derecho, con 4 obras, y la literatura, con 3 , las áreas temáticas con mayor proyección.

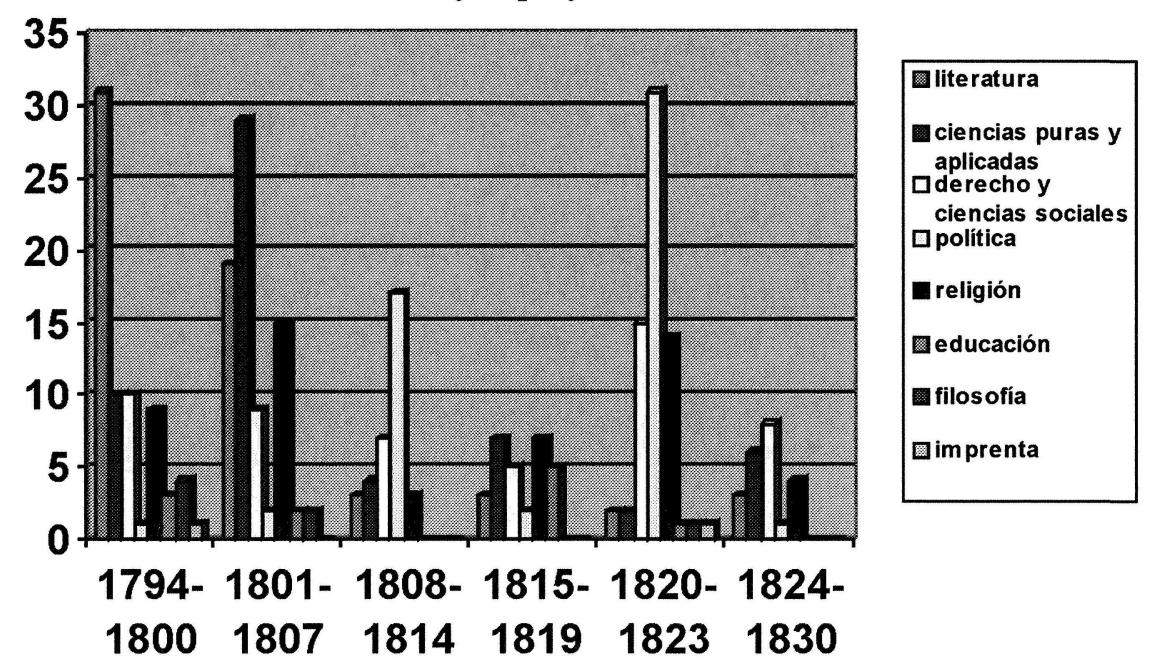

Diferenciación por materias de la producción de la imprenta Villalpando según el contexto político (incluyendo reediciones) 
Por lo que respecta a la literatura, si distinguimos por géneros las obras literarias, vemos que la narrativa está representada por 26 obras -que suponen el $48 \%$-, frente a 14 obras respectivas para el teatro y la poesía, representado cada uno con un $26 \%$ (no hemos considerado aquí el caso de 8 reediciones de obras literarias). Si prestamos atención a la distribución quinquenal de los distintos géneros para todo el periodo estudiado, se nos hace evidente, en primer lugar, la práctica desaparición de la vertiente literaria de la producción de la imprenta desde 1809 hasta el evidente canto de cisne de los años 1829-1830, en que tiene lugar un cierto despunte de la narrativa. Los lustros 1794-1798 y 1799-1803, son los años de mayor presencia de publicaciones literarias, con 18 y 19 obras. Significativamente, mientras en el primer lustro domina la narrativa, que logra un techo que no será superado de 11 obras, en el segundo de estos lustros es el teatro, con 8 , el género que reúne mayor número de impresiones. En el primer lustro, destacan las sátiras costumbristas de nuevos usos y modas de fray Juan Fernández de Rojas (1795) y Juan Antonio de Iza Zamacola (1796), escritas con mordacidad y autoconciencia humorística, a las que pueden asimilarse El ropavejero literario en las ferias de Madrid (1796), publicada por un supuesto Desiderio Cerdonio y la primera edición española del poema Lima por dentro (1798) de Esteban de Terralla y Landa ${ }^{61}$. Las prensas de Villalpando ponen a disposición del lector español la Clara Harlowe de Richardson (1794-1795) ${ }^{62}$ y el Hamlet de Shakespeare. En el segundo lustro destaca la primera edición de El barón de Moratín (1803), la traducción de Misantropía y arrepentimiento de Kotzbue por García de Arrieta, el Teatro español

61 [Juan Antonio DE IZA ZAMACOLA], Elementos de la ciencia contradanzaria, para que los currutacos, pirracas, y madamitas del nuevo cuño puedan aprender por principios á baylar las contradanzas por sí solos, ó con las sillas de su casa, \&c. \&c. \&c. Su autor don Preciso. Segunda edicion, Madrid, En la Imprenta de Fermin Villalpando, Año 1796, LVIII + 174 pp., 12. Ejemplar en RAE, signatura S. Coms. 12-E-101.

Simón AYANQUE [Esteban DE TERRALla Y LANDA], Lima por dentro y fuera en consejos económicos, saludables, políticos y morales que da un amigo a otro con motivo de querer dexar la Ciudad de México por pasar a la de Lima. Obra jocosa y divertida en que con salados conceptos se describen, además de otras cosas, las costumbres, usos y mañas de las madamitas de allí, de acá y de otras partes. La da a luz Simón Ayanque, para escarmiento de algunos y entretenimiento de todos, Madrid, imprenta de Villalpando, 1798, XII + 192 pp., 12 ${ }^{\circ}$. Ejemplar en Ministerio de Asuntos Exteriores (Madrid), signatura 14610.

62 Villalpando sólo dio a luz los vols. III y IV de la novela de Samuel Richardson; los vols. I y II son debidos a Benito Cano; la Viuda de García imprimió los vols. VII-IX; Cruzado el X y la Viuda e Hijos de Marín el XI: Samuel RICHARDSON, Clara Harlowe. Novela, traducida del inglés al francés por Mr. Le Tourneur, siguiendo en todo la edición original, revista por su autor Richardson, y del francés al castellano por Don Joseph Marcos Gutiérrez, Madrid, 1794-1795, 11 vols., 8. Ejemplar en Biblioteca de Catalunya, signatura A. 84-8. ${ }^{\circ}-396 / 405$. 
burlesco de Trigueros (1802) y las reediciones de la traducción del Gil Blas debida al padre Isla (1799 y 1800).

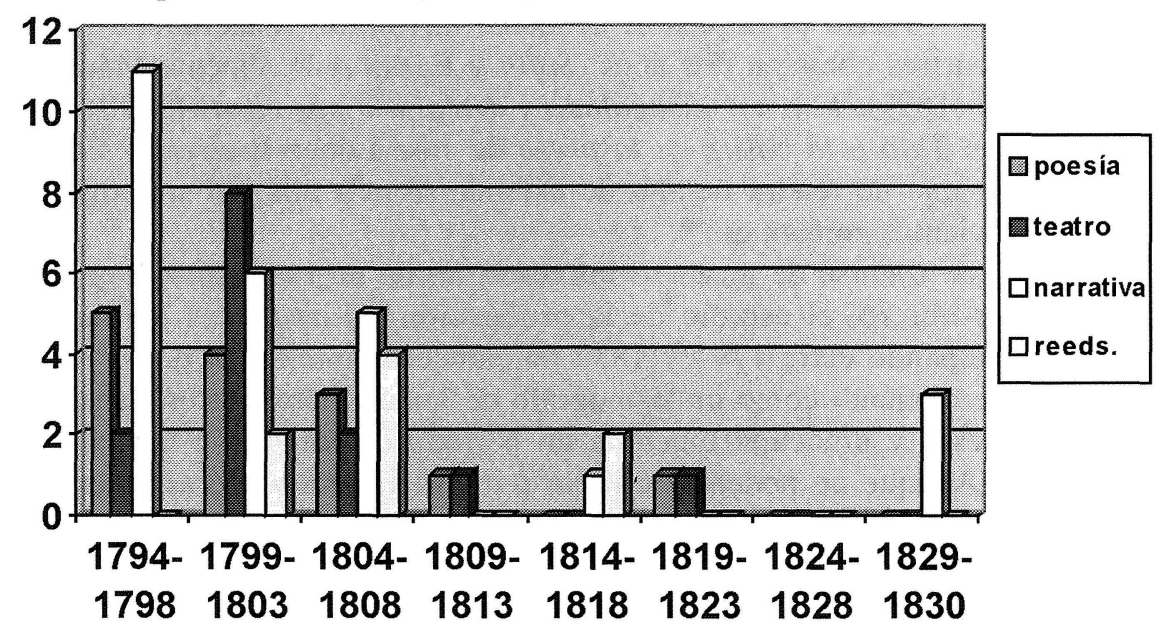

Distribución de los géneros literarios para el periodo 1794-1830

El lustro 1804-1808 dedica 14 obras a la literatura, entre las que destacan las primeras ediciones de La mojigata (1804) y El sí de las niñas (1805), ambas reeditadas en 1806, junto a las traducciones de novelas sentimentales y educativas como Félix y Paulina o el sepulcro del monte Jura de Pierre Blanchard (1806), y la Eufemia o la mujer instruida basada en la Elisa del alemán Campe (1806) ${ }^{63}$. Los años 1809-1813 apenas dejan rastro literario; únicamente es posible destacar la traducción de La escuela de los maridos de Molière debida a Moratín (1812). Crisis de las bellas letras que continúa entre 1814 y 1818 . Cuando en 1817, Juan de Dios Polo del Aguila comenzó a reimprimir su versión de Félix y Paulina, se encontró con la prohibición de su lectura por el Supremo Tribunal de la Inquisición, "por contener expresiones obscenas y máximas contrarias a nuestra sagrada religión». A pesar de pedir nuevas calificaciones y obtener alguna positiva, su petición se denegó definitivamente por la Inquisición de Corte en octubre de $1819^{64}$. Los tiempos habían cambiado. La única relativa novedad de estos años la aporta la publicación de la novela El subterráneo o las dos hermanas Matilda y

${ }^{63}$ Pierre Blanchard, Félix y Paulina o el sepulcro al pie del monte Jura. Obra escrita en francés por P. Blanchard. Traducida del francés por $D$. $V$. A. [Juan de Dios Polo del Águila], Madrid, Villalpando, 1806, 2 vols., $8^{\circ}$. Sin ejemplar localizado.

J. Heinrich CAMPE, Eufemia o la mujer instruida. Sacada de la Elisa del célebre alemán Joaquín Enrique Campe, Madrid, Villalpando, 1806, $8^{\circ}$. Seminario Conciliar (Madrid), signatura 3/111-7-12. Reeditada por Villalpando en 1818.

${ }^{64} \mathrm{Vid}$. su expediente de impresión en AHN, Inquisición, leg. 4518 (16). 
Leonor (1817), de la inglesa Sophie Lee ${ }^{65}$. Entre 1819 y 1828 pasma la práctica desaparición de la literatura, tanto por lo que respecta a la calidad como a la cantidad. Muerto el impresor, acontece un tímido renacimiento de la narrativa, con tres obras en dos años: Sofía y Enrique de Vicenta Maturana de Gutiérrez (1829), El amor disimulado y declarado por cifras (1830) y La filósofa en el Tajo o la casita en la presa de José López Escovar y Carbonera (1830); que no tendrá tiempo de extenderse más allá, en sintonía con los nuevos vientos románticos ${ }^{66}$.

A pesar de tratarse de un mero impresor, no de un impresor-editor o de un impresor-librero, el estudio de la producción salida de las prensas de Fermín Villalpando entre 1794 y 1830 no carece de interés, al poder representarse este conjunto como un sismógrafo de los diversos gustos, sensibilidades, intereses y preocupaciones de un periodo de transición tan largo y conflictivo. Aunque no podemos afirmar que estuviese situado en la primera fila editorial y tipográfica, sus prensas difundieron las obras de algunos de los principales escritores y publicistas de su tiempo. Su actividad, que sería necesario comparar con la de otros impresores de esas décadas - pienso en Benito Cano y José Doblado, por ejemplo-, es un valioso marco en que considerar las fracturas y continuidades de unas épocas y reinados que hasta hace muy poco, en aras de la simplificación histórica y literaria, han sido colocados espalda contra espalda ${ }^{67}$.

${ }^{65}$ Sophie LEE, El subterráneo o las dos hermanas Matilda y Leonor. Novela compuesta en inglés por Mistriss Lee; traducida al Castellano y corregida perfectamente en esta última edición, Madrid, Imprenta de Villalpando, 1817, 3 vols., $12^{\circ}$. Ejemplares en Real Academia de Ciencias Morales y Políticas (Madrid), signaturas 9989/9990: vols. I y II; y Biblioteca Pública del Estado (Toledo), signaturas 4-20335/4-20336. Falta vol. I.

${ }^{66}$ Vicenta MATURANA DE GUTIÉRREZ, Sofía y Enrique. Novela original escrita y dedicada a su alteza real la serenissima señora Infanta doña María Francisca de Asís por Vicenta Maturana de Gutiérrez, Madrid, imprenta de la viuda de Villalpando, 1829, 2 vols., $8^{\circ}$. Ejemplar en Museo Romántico (Madrid), signaturas P-II-12 (I) / P-II-12 (II).

El amor disimulado y declarado por cifras: novela original compuesta por D. A. G. V. C., Madrid, Imp. Vda. de Villalpando, 1830,142 pp., $8^{\circ}$. Ejemplar en BNM, signatura 7-95214.

José López Escovar y CARbonera, La Filosofa en el Tajo ó La Casita en la Presa: novela moral que contiene otros, Madrid, Imprenta de la viuda de Villalpando, 1830, 180 pp., $8^{\circ}$. Ejemplar en RAE, signatura 22-X-61.

${ }^{67}$ La obra colectiva, arriba citada, de J. Álvarez BARRIENTOS (ed.), Se hicieron literatos para ser políticos. Cultura y política en la España de Carlos IV y Fernando VII (2004), supone todo un ejemplar esfuerzo en el reexamen de las pervivencias y discontinuidades culturales e ideológicas de estos dos momentos históricos, que tiene otro paralelo en los más recientes libros de R. P. Sebold en torno a la poesía y la novela. 


\section{APENDICE DOCUMENTAL}

1. Testamento conjunto de Fermín Tadeo Villalpando y su mujer Margarita Guerra, otorgado ante el escribano Dionisio Pérez, el 1 de octubre de 1817 (APM, tomo 23919, fol. 457 y ss.)

En el Nombre de Dios Todopoderoso Amen. Sea notorio que Nos Don Fermin Tadeo Villalpando, y Doña Margarita Guerra, lexitimos consortes vecinos de esta Villa de Madrid, naturales de la ciudad de Valladolid: Y yo el susodicho, hijo legitimo y de legitimo matrimonio de Don Gaspar Villalpando, natural de la villa de Valderas de Campos, y Doña Rosa Garcia que lo fue de Medina del Campo: Y yo la Doña Margarita hija legitima de legitimo matrimonio de $\mathrm{D}^{\mathrm{n}}$ José Guerra y Doña Nicolasa Acosta, naturales de la expresada ciudad, todos difuntos: Hallandonos con perfecta salud, dando gracias por tal beneficio á la Divina Providencia, y por su infinita misericordia en nuestro juició y entendimiento natural creyendo como firmemente creemos en el infalible misterio de la Santisima Trinidad, Padre, Hijo y Espiritu Santo, tres personas distintas y una en esencia, y en todo lo demás que creé y confiesa la Santa Madre Yglesia Catolica, Apostolica, Romana, en cuya fé y creencia hemos vivido y protestamos vivir y morir como Catolicos fieles Cristianos: Temerosos de la muerte cierta á todo viviente y su hora dudosa, deseando estar prevenidos para quando llegue, tomamos por nuestra Abogada á María Santisima, Angel de Nuestra Guarda, Santos de nuestros nombres, de nuestra devocion y demás de la Corte Celestial para que intercedan con nuestro $\mathrm{S}^{\mathrm{r}}$ Jesucristo y nuestro Redentor, lleve nuestras almas á su Santa Gloria, y bajo de esta protestacion é invocacion Divina: Otorgamos: que hacemos nuestro testamento en la forma siguiente:

Encomendamos nuestras almas á Dios Nuestro Señor que las crió y redimió con su preciosa sangre, pasion y muerte, y el cuerpo mandamos a la tierra de que fué formado, el qual cadaver, siendo amortajado con el hábito de San Francisco, colocado en casa propia cubierto del mismo sayal se le dé sepultura, que será en el Cementerio de la Parroquia donde falleciese, y la hora y disposicion del entierro lo dexamos á eleccion del sobreviviente, y con arreglo á lo que nos tenemos prevenido.

Que el día de nuestro entierro ó al siguiente se diga por nuestras Almas, misa de cuerpo presente, con Diacono, Subdiacono, vigilia y responso dandose la limosna acostumbrada.

Que ademas de la dicha se celebren $\mathrm{p}^{\mathrm{r}}$ el Alma de cada uno de Nos, cien misas rezadas con limosna de seis $\mathrm{r}^{\mathrm{s}}$ cada una la quarta parte en la Parroquia; y las setenta y cinco restantes las mandará decir el sobreviviente en la Yglesia que mas le acomode y guste.

Que asi mismo se manden decir por el Alma de cada uno de Nos, quatro misas rezadas con limosna de diez reales cada una en el Altar de $\mathrm{N}^{\text {tra }} \mathrm{S}^{\text {ra }}$ de la Soledad del Conb ${ }^{\text {to }}$ de la Victoria; y otra misa rezada y con igual limosna en el Altar de la misma imagen de la Soledad de la capilla de la calle de la Paloma, llevando además á cada una de estas soberanas Señoras, una libra de cera para su culto. 
Que en lugar de hacerse honras ó misa de Novenario por nuestras Almas, és voluntad se manden celebrar por la de cada uno de Nos, las quarenta y ocho misas que llaman de San Vicente Ferrer, encargandose su cumplimiento dentro de los nueve dias inmediatos á nuestro fallecimiento con la limosna acostumbrada y donde eligiese el sobreviviente, advirtiendo que durante nuestra vida las hubieremos mandado decir, constará por recibo el cumplimiento de esta $\mathrm{n}^{\text {tra }}$ voluntad.

Que á los Santos Lugares de Jerusalen, Redencion de Cautivos Cristianos, Reales Hospitales, General y Pasion de de esta Corte, y Manda Pía forzosa establecida con el objeto de socorrer los Prisioneros, familias de estos, y demás personas que hayan padecido en la ultima Guerra, queremos se las dé á ésta los doce reales mandados por S.M. y á todos aquellos la limosna acostumbrada, con lo que les separamos del $\mathrm{d}^{\text {ro }}$ que pudiesen haber y pretender á nuestros bienes.

Declaramos que al tiempo de contraher $\mathrm{n}^{\text {tro }}$ matrimonio, formalizamos los competentes resguardos de carta de dote y capital de los bienes y caudal que a cada uno correspondía, y entre otros la Ymprenta que Yo el otorgante tenia establecida, y en la actualidad nos hallamos con ella, compuesta de diferentes fundiciones, y quatro prensas de Ymprimir, con todos los enseres pertenecientes a la misma y varias Ympresiones de libros en paquetes y enquadernados, todo propio y privativo nuestro.

Así mismo declaramos que al presente tenemos contrahidas algunas deudas aunq ${ }^{\text {e }}$ de corta consideracion é igualmente se nos deben otras cantidades mayores que por estar proxima su cobranza y por consiguiente el pago de aquellas omitimos expresar aquí, y en el caso de que al tiempo de nuestro fallecimiento no se hubiere verificado lo uno ni lo otro, queremos que $\mathrm{p}^{\mathrm{r}}$ el sobreviviente se cobre lo que se nos deba y se satisfaga y se pague lo que debiesemos según constará de los libros de asientos y de varios recivos sueltos de los respectivos deudores que se hallaran en nuestro poder.

Tambien declaramos que al tiempo de nuestro fallecimiento dexaremos una Memoria firmada de nuestro puño, juntos o separadamente en $\mathrm{q}^{\mathrm{e}}$ nos reservamos aumentar, quitar ó variar en lo que se nos ofrezca lo ordenado en este nuestro testamento, ó hacer mandas, legados, ó prevenciones, según permitan las circunstancias del tiempo; y queremos que quanto en ella se expresare se guarde y cumpla inviolablemente como parte crucial de esta disposición, con que se una y protocolice para que siempre conste.

Y para cumplir y pagar lo contenido en este Testamento, Memoria citada y demás que legitimamente se deba, nos nombramos uno á otro por Albaceas y testamentarios, y al Licenciado Don Fran ${ }^{\text {co }}$ Mateo Manchamalo, Abogado del Ylt ${ }^{\text {re }}$ Colegio de esta Corte, á Don Santiago Arroyo, Pror del número de la misma y á $\mathrm{D}^{\mathrm{n}}$ Fernando Aguado, empleado de la Direccion de la Real Loteria, y todos vecinos de esta villa y á cada uno insolidum, y nos damos Poder y á los sobredichos según requiera para que al fallecimiento de qualquiera de Nos, se apoderen de los bienes y caudal que dejasemos tomando y vendiendo los necesarios en publica almoneda ó fuera de ella, satisfagan quanto queda expresado durando á todos el car- 
go de tal el tiempo que se necesitare aunque sea pasado el prevenido por derecho, y mucho mas que nos prorrogamos y á los mismos.

$\mathrm{Y}$ en todos los demás nuestros bienes, derechos, acciones y futuras subcesiones que en esta Corte ó fuera de ella donde quiera que sea nos pudiesen tocar y corresponder, nos instituimos y nombramos uno á otro por herederos mediante á no tener ascendientes ni descendientes forzosos $\mathrm{p}^{\mathrm{a}}$ que quanto sea lo haya y lleve el sobreviviente con la bendicion de Dios á quien pedimos nos encomendemos.

Y por el presente rebocamos, anulamos, damos por rotos, nulos de ningun valor ni efecto qualesquier testamento y poderes para hacerlos, cobdicilos y demás disposiciones que antes de ahora hayamos hecho ni otorgado por escrito, de palabra ó en otra forma, para que ninguna valga ni haga fé, en juicio ni fuera de el, y solo este testamento y la Memoria citada se há de guardar y cumplir por $\mathrm{n}^{\text {tra }}$ última y deliberada voluntad en la forma que haya lugar en derecho. Y en su testimonio así lo otorgamos y firmamos ante el presente escribano de S.M. y del Colegio de Notarios domiciliados en esta Heroyca Villa de Madrid en ella á primero del mes de Octre del año de mil ochocientos diez y siete, siendo testigos $\mathrm{D}^{\mathrm{n}}$ Vicente Mingueza, Don Gregorio Gonzalez, Don Manuel Garcia Durán, $\mathrm{D}^{\mathrm{n}}$ Fran $^{\text {co }}$ Alcazar y $\mathrm{D}^{\mathrm{n}}$ Gregorio del Campo y Torres, vec ${ }^{\mathrm{s}}$ y residentes en la misma, a quienes y otorgtes Yo el Ynfrascripto Escribano doy fé conozco $=$ Fermín Tadeo Villalpando $=$ Margarita Guerra $=$ Ante mí Dionisio Perez =

Yo el Ynfrascripto Escribano de S.M. Notario de su Reyno, vecino y del Colegio de esta Corte, presente fui, y en fé de ello consigno y firmo día de su otorgamiento en estas quatro foxas de los sellos tercero y quarto Mayor, en el que queda su rexistro y notada esta saca. = Valga =

Dionisio PEREz [rubricado]

2. Memoria testamentaria de Fermín Tadeo Villalpando, otorgada ante el escribano Dionisio Pérez el 11 de octubre de 1828 (APM, tomo 23919, fol. 462 y ss.)

Memoria Testamentaria $q^{e}$ yo $D^{n}$ Fermin Tadeo Villalpando, marido $y$ conjunta persona de $D^{a}$ Margarita Guerra, vez en esta Corte, cito en mi testamento que en concurrencia de la dha mi propia muger otorgamos en 1 de Oct de mil ochocientos diez y siete ante el escribano $R^{l} D^{n}$ Dionisio Perez por la cual ordeno y es mi voluntad se observe, guarde, y cumpla lo $q^{e}$ en esta se contiene, como parte de mi testam ${ }^{t o}$.

Primeram $^{\text {te }}$ declaro $\mathrm{q}^{\mathrm{e}}$ tengo en mi compañía una hermana legitima de padre y madre, soltera y huerfana llamada Josefa Matilde Villalpando, la $\mathrm{q}^{\mathrm{e}}$ quiero y es mi voluntad, que mientras viva subsista en esta mi casa y en compañía de la dha mi muger manteniendola ésta como hasta aquí lo hemos hecho, $\mathrm{y} \mathrm{q}^{\mathrm{e}}$ ademas la contribuya mi muger con un real diario $\mathrm{p}^{\mathrm{a}}$ su decencia, y la pido me encomiende á Dios.

Yt. que si llegase el caso (que no lo espero por la gran satisfaccion $\mathrm{q}^{\mathrm{e}}$ tengo en la prudencia de mi muger) $\mathrm{q}^{\mathrm{e}}$ si por algun incidente se separasen de estar en compañía y no vivan juntas, quiero y es mi voluntad $q^{e}$ 
la referida mi muger la de á la dha mi hermana del producto de la imprenta y de mis bienes cinco $\mathrm{r}^{\mathrm{s}}$ diarios para su manutencion por todo el tiempo de su vida, y asimismo quiero $\mathrm{q}^{\mathrm{e}}$ por una vez la dha mi muger la dé mil $\mathrm{r}^{\mathrm{s}}$ en metalico $\mathrm{p}^{\mathrm{a}}$ ayuda de poner su cuarto.

Yt. que si la dha mi muger Margarita vendiese la imprenta $\mathrm{q}^{\mathrm{e}}$ poseo y es mi propia con todos los enseres pertenecientes á ella, quiero y es mi voluntad $\mathrm{q}^{\mathrm{e}}$ se la den á la referida mi hermana Josefa del todo de aquella y de lo demas mis bienes haran la cantidad de treinta y cuatro mil $\mathrm{r}^{\mathrm{s}}$ en dinero metalico y no en otra especie, y que se suspenda entonces la contribucion de los cinco $\mathrm{r}^{\mathrm{s}}$ diarios.

Yt. es mi voluntad que si dha mi muger muriese antes $\mathrm{q}^{\mathrm{e}} \mathrm{mi}$ hermana que sus herederos contribuyan á dha mi hermana con seis $\mathrm{r}^{\mathrm{s}}$ diarios mientras viva. Y si dhos herederos vendiesen la imprenta quiero la den á la dha mi hermana cuarenta mil $\mathrm{r}^{s}$ en efectivo, y se suspenda la contribucion de los seis $r^{s}$ arriba mencionada.

Yt. que si muriese la citada mi hermana antes que mi muger, bien sea estando juntas ó separadas, es mi voluntad, que mi muger Margarita la pague los gastos de su entierro, siendo una cosa regular, y quiero que á los herederos de la dha mi hermana no se les dé ni contribuya con cosa alguna, pues esto sería en perjuicio de mi muger, pues mi voluntad solo es de que la referida mi hermana disfrute todo lo dicho mientras viva por ser una pobre huerfana y no tener mas amparo $\mathrm{q}^{\mathrm{e}}$ el mio y el de mi muger y la pido me encomiende á Dios.

Yt. es mi voluntad que se manden decir por mi anima dos misas rezadas en el Altar de $\mathbf{N}^{\text {tra }} \mathbf{S}^{\text {ra }}$ de los Cuchillos, que se venera en la Yglesia de las Angustias de la ciudad de Valladolid con la limosna de cuarenta $\mathrm{r}^{\mathrm{s}}$ y que se compre una libra de cera para alumbrar á la misma soberana Ymagen, y este encargo se hará á alga persona de toda satisfaccion $\mathrm{q}^{\mathrm{e}}$ resida en dha ciudad.

Yt. Asimismo ordeno y quiero que de mis bienes se entreguen de limosna á la Congregacion de esclavos del Santisimo Sacram ${ }^{\text {to }}$ sita en el Oratorio del Caballero de Gracia de esta Corte trescientos veinte $r^{s}$ por una vez para el culto del mismo Sacram $^{\text {to }} \mathrm{q}^{\mathrm{e}}$ se venera en dha Yglesia y supc $^{\circ}$ a dhos $S^{\text {res }}$ Congreg ${ }^{\text {tes }}$ se sirvan encomendarme á Dios.

Yt. quiero que al sacerdote ó religioso que me auxilie á bien morir se le den de mis bienes doscientos $\mathrm{r}^{\mathrm{s}}$, limosna de veinte y cinco misas rezadas por sufragio de mi alma y le suplico las celebre en altar privilegiado.

Yt. ordeno $\mathrm{q}^{\mathrm{e}}$ al aprendiz o aprendices $\mathrm{q}^{\mathrm{e}}$ duerman en mi casa, á la criada ó criado $\mathrm{q}^{\mathrm{e}}$ me estuvieren sirviendo al tiempo de mi fallecim ${ }^{\text {to }}$ se les dé alguna cosa de las ropas de mi uso, dejando esto á voluntad de mi muger, y les pido me encomienden a Dios.

Yt. es mi voluntad, que á los oficiales y aprendices asi de caja como de prensa que el dia de mi fallecimiento se hallen trabajando en esta mi imprenta que se les den á los oficiales veinte $\mathrm{r}^{\mathrm{s}}$ á cada uno, y á los aprendices diez $\mathrm{r}^{\mathrm{s}}$ tambien á cada uno y les pido se sirvan acompañar mi cadaver al campo santo, y $\mathrm{q}^{\mathrm{e}}$ me encomienden á Dios.

Yt. ruego y sup ${ }^{c o}$ á la dha mi muger Margarita, $\mathrm{q}^{\mathrm{e}}$ mientras viva, mande decir en cada un año por sufragio de mi alma una misa rezada el dia 
de los Dolores de María SS ${ }^{\text {ma }}$ y en el altar donde se venera la Virgen de la Soledad del conv $v^{\text {to }}$ de la Vitoria de esta Corte con la limosna de diez $\mathrm{r}^{\mathrm{s}}$ y otra misa tambien rezada con igual limosna, y por sufragio de mi alma, en el altar de Jesus Nazareno del conv ${ }^{\text {to }}$ de PP. Trinitarios descalzos de esta Corte.

Yt. declaro que estan mandadas decir las Misas $\mathrm{q}^{\mathrm{e}}$ llaman de $\mathrm{S}^{\mathrm{n}}$ Vicente por sufragio del alma del primero $\mathrm{q}^{\mathrm{e}}$ falte de nosotros dos, y está pagada la limosna acostumbrada, y consta de recibo.

Yt. Asimismo es nuestra deliberada voluntad, que si sucediese el caso no esperado de $\mathrm{q}^{\mathrm{e}}$ uno y otro yo y mi muger muramos con poca diferencia de tiempo, de forma $\mathrm{q}^{\mathrm{e}}$ no podamos otorgar otro nuevo testam ${ }^{\text {to }}$ desde ahora para entonces, instituimos por nuestro herederos en todos los referidos bienes á nuestras dos hermanas Josefa Villalpando y María Guerra, si fuesen vivas, cada una en la parte que á cada uno de nos nos pertenece $\mathrm{y} \mathrm{q}^{\mathrm{e}}$ heredariamos fuera del presente caso; pero con la condicion de $\mathrm{q}^{\mathrm{e}}$ se cumplan con toda exactitud lo $\mathrm{q}^{\mathrm{e}}$ dejamos dispuesto en el referido testamento, y todo lo $\mathrm{q}^{\mathrm{e}}$ aquí vá expresado; y será con la precisa obligacion de que han de dar diez mil $\mathrm{r}^{\mathrm{s}}$ de limosna por iguales partes, $\mathrm{y}$ en estos terminos, cuatro mil $\mathrm{r}^{\mathrm{s}}$ en metalico al Colegio de niñas de la Paz; otros cuatro mil al Conv ${ }^{\text {to }}$ de Capuchinas de la Villa de Pinto, y los dos mil restantes los distribuirán en misas con la limosna de seis $\mathrm{r}^{\mathrm{s}}$ cada una, doscientas en la Yglesia de la Buena Dicha y las restantes donde gusten mandarlas decir, esto en el caso de $\mathrm{q}^{\mathrm{e}}$ yo ó mi muger Margarita no lo hayamos hecho en vida, lo $\mathrm{q}^{\mathrm{e}}$ procuramos hacerlo y constará de recibos.

Yt. Atendiendo á la ausencia y ocupaciones $\mathrm{q}^{\mathrm{e}}$ en el dia tienen los dos testament ${ }^{s}$ nombrados en nuestro testamento les exhoneramos de este encargo y en su lugar nombramos por nuestros Albaceas y testamentarios á $\mathrm{D}^{\mathrm{n}}$ Miguel de Luque Roldan, $\mathrm{n}^{\text {tro }}$ herm $^{\circ}$ politico, á $\mathrm{D}^{\mathrm{n}}$ Anselmo de Leon Barradas, Abogado del Colegio de esta Corte, y á $\mathrm{D}^{\mathrm{n}}$ Santiago Arroyo Procurador del $\mathrm{N}^{\circ}$ de esta Villa, todos vecinos de ella, á quienes damos poder especial y el $\mathrm{q}^{\mathrm{e}}$ en $\mathrm{d}^{\text {cho }}$ se requiere y á cada uno in solidum para poder cumplir todo lo expresado en el refo testamento, y cuanto en esta $\mathrm{Mem}^{\mathrm{a}}$ testamentaria va especificado, por ser esta nuestra deliberada voluntad, y que mancomunadam ${ }^{\text {te }}$ lo firmamos en Madrid á once de octubre de mil ochocientos veinte y ocho.

Fermin TADEo Villalpando [rubricado] MARgarita GuerRa [rubricado]

$\mathrm{D}^{\mathrm{a}}$ Margarita Guerra, vecina de esta Corte y de estado viuda de D. Fermin Tadeo Villalpando, ante VS como mas haya lugar digo: Que el citado mi marido ha fallecido en el dia 19 de febrero ultimo bajo del testamento que ambos otorgamos el 1 de octubre de 1817 ante el escribano $R^{1} D$. Dionisio Perez que original presento por el qual se vé que en una de sus clausulas ordenamos ambos que dejariamos una Memoria firmada de nuestro puño juntos ó separadamente que es la que tambien presento, y a fin de que se guarde y cumpla inviolablemente como parte esencial de dha disposicion y no se dude en lo sucesivo su contenido. 
A VS supp ${ }^{\mathrm{co}}$ que haviendo por presentado dho testamento y memoria se sirva mandar protocolizar esta con aquel en los registros del citado escribano Real D. Dionisio Perez por este testimonio integro de todo por ser conforme á justicia que pido para $\&^{a}=$

Margarita GUERRA [rubricado] 


\title{
RESUMEN
}

Un impresor ante la crisis de las Luces: Fermín Villalpando (1794-1830), por Gabriel Sánchez Espinosa.

Partiendo de una serie de análisis cuantitativos, este artículo estudia la producción del impresor Fermín Villalpando, activo en Madrid entre 1794 y 1830. Durante su carrera, que se extiende entre el reinado de Carlos IV, la Guerra de la Independencia y la restauración bajo Fernando VII, Villalpando imprimió un total de 281 títulos diferentes, encuadrados en un variado conjunto de temas (pensamiento, viajes, poesía, teatro, clásicos españoles, medicina, derecho, religión), que reflejan como un sismógrafo las modas culturales, los vaivenes políticos y la incertidumbre social de estas difíciles décadas (así, por ejemplo, en 1821 comparten su sello editorial Jeremy Bentham, Cesare Beccaria y fray Diego José de Cádiz). Muy cuidadoso con el diseño material, la imprenta de Villalpando se especializará en un libro de bolsillo que combina una bella factura con una serena apariencia neoclásica.

Palabras clave: Fermín Villalpando - historia de la imprenta española - producción de libros entre la Ilustración y el Romanticismo - L. Fernández de Moratín - M. Godoy.

\begin{abstract}
Taking as its point of departure an exhaustive series of cuantitative analysis, this article studies the production of the printer Fermín Villalpando, active in Madrid between the years 1794-1830. Throughout his business career, which extended from the reign of Charles IV to the restoration of the absolutist monarchy under Ferdinand VII (having been able to survive the dramatic and fateful years of the Peninsular War), Villalpando printed a total of 281 different works, covering a broad spectrum of topics (new thought, travel literature, poetry, theatre, Spanish classics, medicine, law, religion), all of which reflect, as would a seismograph, the political unrest and changing cultural fashions of these difficult decades. (In 1821, for example, he printed in his presses works by Jeremy Bentham, Cesare Beccaria and Fray Diego José de Cádiz). Characteristically, the Villalpando press always took special care with the material design and presentation of its books, specializing in small formats that combine beautiful workmanship with a serene Neoclassical design.
\end{abstract}

Key words: Fermín Villalpando - Spanish printing history - book production between the Enlightenment and Romanticism - L. Fernández de Moratín - M. Godoy. 